NBER WORKING PAPER SERIES

\title{
DOWN OR OUT: \\ ASSESSING THE WELFARE COSTS \\ OF HOUSEHOLD INVESTMENT MISTAKES
}

\author{
Laurent E. Calvet \\ John Y. Campbell \\ Paolo Sodini \\ Working Paper 12030 \\ http://www.nber.org/papers/w12030 \\ NATIONAL BUREAU OF ECONOMIC RESEARCH \\ 1050 Massachusetts Avenue \\ Cambridge, MA 02138 \\ February 2006
}

We thank Statistics Sweden for providing the data. We received helpful comments from Francis Kramarz, Massimo Massa, Bruno Solnik, Tuomo Vuolteenaho and seminar participants at CREST, Harvard University and Riksbank. The project benefited from excellent research assistance by Daniel Sunesson. This material is based upon work supported by the Agence Nationale de la Recherche under a Chaire d'Excellence to Calvet, BFI under a Research Grant to Sodini, the HEC Foundation, the National Science Foundation under Grant No. 0214061 to Campbell, Riksbank, and the Wallander and Hedelius Foundation. The views expressed herein are those of the author(s) and do not necessarily reflect the views of the National Bureau of Economic Research.

(C2006 by Laurent E. Calvet, John Y. Campbell, and Paolo Sodini. All rights reserved. Short sections of text, not to exceed two paragraphs, may be quoted without explicit permission provided that full credit, including (C) notice, is given to the source. 
Down or Out: Assessing the Welfare Costs of Household Investment Mistakes

Laurent E. Calvet, John Y. Campbell, and Paolo Sodini

NBER Working Paper No. 12030

February 2006

JEL No. D5, D9, E3, O1

\begin{abstract}
This paper investigates the efficiency of household investment decisions in a unique dataset containing the disaggregated wealth and income of the entire population of Sweden. The analysis focuses on two main sources of inefficiency in the financial portfolio: underdiversification of risky assets ("down") and nonparticipation in risky asset markets ("out"). We find that while a few households are very poorly diversified, the cost of diversification mistakes is quite modest for most of the population. For instance, a majority of participating Swedish households are sufficiently diversified internationally to outperform the Sharpe ratio of their domestic stock market. We document that households with greater financial sophistication tend to invest more efficiently but also more aggressively, so the welfare cost of portfolio inefficiency tends to be greater for these households. The welfare cost of nonparticipation is smaller by almost one half when we take account of the fact that nonparticipants would be unlikely to invest efficiently if they participated in risky asset markets.
\end{abstract}

Laurent E. Calvet

Department of Finance

HEC School of Management

1, rue de la Liberation

78351 Jouy en Josas Cedex

France

and NBER

calvet@hec.fr

John Y. Campbell

Department of Economics

Harvard University

Littauer Center 213

Cambridge, MA 02138

and NBER

john_campbell@harvard.edu
Paolo Sodini

Department of Finance

Stockholm School of Economics

Sveavagen 65, Box 6501

SE-113 83 Stockholm, Sweden

paolo.sodini@hhs.se 


\section{Introduction}

Modern financial markets offer a rich array of investment opportunities. Households in developed countries can accumulate liquid wealth in bank accounts, money market funds, bond funds, equity mutual funds, individual bonds and equities, financial products with insurance features such as annuities and capital insurance funds, and derivative securities. In addition, many households have significant wealth in less liquid forms such as real estate and private businesses.

How do households exploit these investment opportunities? Do they typically follow the precepts of standard financial theory such as participation (taking at least small amounts of compensated risk) and diversification (avoiding uncompensated risk)? To the extent that they deviate from these precepts, are the costs of such deviation modest, and therefore explicable by relatively small frictions ignored in standard theory, or are they large and accordingly hard to rationalize? How heterogeneous are household investment strategies? Are cross-sectional differences in investment strategies correlated with observable household characteristics such as age, education, and wealth?

These questions are of central importance in economics and finance, but reliable answers are extremely hard to obtain because they require a high-quality dataset on investment strategies. To study household portfolios, we would like to have data with at least five characteristics. First, the data should include a representative sample of the population. Second, for each household, the data should measure both total wealth and an exhaustive breakdown of wealth into relevant categories. Third, these categories should be detailed enough to distinguish between asset classes, and for some issues - notably the question of diversification - we would like to observe holdings of individual assets. Fourth, the data must be accurately reported. Finally, we would like to follow households over time so we would like to have panel data rather than repeated cross-sections.

Most work on household portfolio choice relies on surveys. The US survey with the best data on financial wealth is generally thought to be the Survey of Consumer Finances $(\mathrm{SCF}){ }^{1}$ The SCF is representative and measures all components of wealth, but it reports holdings of broad asset classes rather than specific financial assets, it relies on the accuracy of household financial reporting, and it does not follow households over time. Accordingly there has recently been interest in alternative data sources that

\footnotetext{
${ }^{1}$ Recent studies that use the SCF include Bergstresser and Poterba (2004), Bertaut and StarrMcCluer (2002), Carroll (2002), Heaton and Lucas (2000), Poterba and Samwick (1997), Tracy and Schneider (2001), and Tracy, Schneider and Chan (1999). Other surveys of wealth are the Wharton Survey conducted in the 1970's (Blume and Friend 1978) and the UBS/Gallup survey (Graham, Harvey, and Huang 2005 and Vissing-Jorgensen 2003), both of which rely on telephone interviews, and the Health and Retirement Survey (Juster, Smith, and Stafford 1999) which has high quality data but only on older households.
} 
remedy these deficiencies. Following the pioneering work of Schlarbaum, Lewellen, and Lease $(1978)$ and Odean $(1998,1999)$, a number of authors have looked at the account records of individual investors reported by a brokerage house. ${ }^{2}$ These brokerage records are highly accurate reports of holdings and trades in individual stocks, but they sample customers of the brokerage house rather than the entire population and do not necessarily represent total wealth even of these customers, who may also have other accounts elsewhere. Similar difficulties afflict recent studies of asset allocation in 401(k) accounts and other tax-favored retirement accounts. ${ }^{3}$

Government tax records are a tried-and-true source of accurate financial data. The US tax system requires reporting of wealth only in connection with the estate tax, which is levied only on the holdings of the very rich at the date of death. Blume and Friend (1978) and Kopczuk and Saez (2004) have used US estate tax records to study household asset allocation. In Sweden, by contrast, households are liable to pay a wealth tax throughout their lives, and this has led the Swedish government to construct detailed records of households' financial assets. In this paper we use Swedish government records to construct a panel of wealth and income data covering the entire population of Sweden (about 9 million residents). The dataset provides highly disaggregated information on the income, wealth, demographic composition, education and location of all households. Individual financial asset, mutual fund and real estate portfolios are provided at the single property and security level. Each individual can be followed over time. The income data begin in 1983 and the wealth data in 1999. Our dataset gives us the unique opportunity to analyze the financial behavior of the entire population of an industrialized country.

There is some earlier work by Massa and Simonov (2003) on the portfolios of Swedish households. Massa and Simonov do not make direct use of Swedish government records. Instead, they begin with an income and wealth survey, Longitudinal Individual Data for Sweden (LINDA), which describes a representative sample of about $3 \%$ of the Swedish population. LINDA contains high-quality data on income, real estate, and overall taxable wealth, but gives limited information about the components of financial wealth. Only the share of each household's wealth invested in risky assets and its bank account balance are available. Massa and Simonov merge LINDA with a dataset on individual stock ownership of Swedish companies from 1995 to 2000. Stock ownership data were available in this period since Swedish companies were legally required to report the identity of most of their shareholders. These reporting requirements did not apply to

\footnotetext{
${ }^{2}$ Recent papers using brokerage house data include Barber and Odean (2001), Zhu (2002), Goetzmann and Kumar (2004), Ivkovic and Weisbenner (2003), and Ivkovic, Sialm, and Weisbenner (2004).

${ }^{3}$ Recent studies of such accounts include Agnew, Balduzzi, and Sunden (2003), Ameriks and Zeldes (2004), Benartzi and Thaler (2001), Choi, Laibson, Madrian, and Metrick (2002, 2004), and Madrian and Shea (2001).
} 
mutual funds or to bond issuers, and thus Massa and Simonov cannot measure bond or mutual fund holdings. Their dataset, like the brokerage records used by Odean (1998, 1999), can be used to measure biases in households' decisions with respect to individual stocks, but not the overall degree of diversification in household portfolios.

We estimate the means and variances of household portfolio returns using standard asset pricing models, and obtain four main sets of results. First, a large fraction of households incurs modest diversification losses in their financial portfolios of mutual funds, stocks and cash. This result is robust to the choice of asset pricing models or diversification measures. Earlier researchers such as Blume and Friend (1975), Kelly (1995), and Goetzmann and Kumar (2004) have found that households own severely underdiversified portfolios of individual stocks; but we show that mutual funds and cash dominate direct stockholdings in many household portfolios and thus play a crucial role in explaining low diversification losses. A majority of participating households actually outperform the Sharpe ratio of their domestic market, which can be explained by the substantial share of international securities in popular mutual funds.

Second, households with greater financial sophistication, as measured for instance by wealth or education, tend to invest more efficiently but also more aggressively. More specifically, the financial portfolios of sophisticated households have higher Sharpe ratios but also higher volatility. As a result, sophistication generally has an ambiguous effect on the average return loss. In Sweden, we find that the cost of underdiversification is larger for more sophisticated households.

Third, the paper confirms earlier empirical findings on individual portfolios in a highly reliable and comprehensive dataset. We thus report that Swedish households exposed to more background risk, such as entrepreneurs (Heaton and Lucas 2000) or large families, tend to invest less aggressively and more efficiently. Similarly, our finding that richer households attain higher Sharpe ratios seems consistent with earlier research documenting a positive link between rationality and wealth (Vissing-Jorgensen 2003).

Fourth, we verify that variables traditionally associated with nonparticipation, such as low education and low wealth, also tend to characterize poor diversification. This result suggests that nonparticipating households would probably invest poorly if they entered risky asset markets. We show that the welfare costs of nonparticipation are lower by almost one half when underdiversification costs are taken into account. Agents who are "out" would likely be "down" if they entered financial markets.

The organization of the paper is as follows. Section 2 presents the data. In Section 3 , we describe asset allocation at the aggregate and household levels and ask what characteristics make a household more likely to participate in risky asset markets. Section 4 investigates the diversification of Swedish household portfolios, using a mean-variance framework. Section 5 relates portfolio efficiency to household characteristics and derives implications for the welfare cost of nonparticipation. Section 6 asks how investment 
behavior has changed over time, and Section 7 concludes. An Appendix describes our methods in detail.

\section{Data Summary}

We begin the presentation of the dataset with a brief description of the Swedish economy and tax system. Sweden is an industrialized nation with a population of 9 million. The GDP per capita in 2002 is estimated at $\$ 27,300$ when currencies are converted at PPP; this is slightly higher than the EU average of $\$ 26,000$. A large fraction of GDP is controlled by the Swedish government. Total tax revenue amounted to $56 \%$ of GDP in 2002. Government expenditure includes transfers (25\% of GDP in 2002), operating expenses (28\%) and investment (3\%). Because of the large scale of government transfers, Sweden is characterized by a large middle class and lower inequality in disposable income than most other industrialized nations.

Swedish households are subject to both a capital income tax and a wealth tax. Capital income (interest, dividends and capital gains) is taxed at a flat rate of $30 \%$, with deductions allowed for interest paid and capital losses. The wealth tax is paid on all the assets of the household, including real estate and financial securities, with the important exception of private businesses. ${ }^{4}$ It is levied at a rate of $1.5 \%$ on taxable wealth above a threshold, which was equal to 2,000,000 Swedish kronas (SEK) for married couples and 1,500,000 SEK for single taxpayers in 2002. The Swedish krona traded at $\$ 0.1127$ at the end of 2002, so these thresholds correspond to $\$ 225,000$ for married couples and $\$ 170,000$ for single taxpayers. In $2002,263,000$ individuals paid $\$ 430$ million between them in wealth tax. We refer the reader to Taxes in Sweden 2004 for further details.

Because of the existence of the wealth tax, the government's statistical agency, Statistics Sweden (also known by its Swedish acronym SCB), has a parliamentary mandate to collect household-level data on wealth. Statistics Sweden compiles information on household finances from a variety of sources, including the Swedish Tax Agency, welfare agencies, and the private sector. Financial institutions supply information to the tax agency on their customers' deposits, interest paid or received, security investments and dividends. Employers similarly supply statements of wages paid to their employees. In April, taxpayers receive a tax return on which all the data supplied by employers and financial institutions has already been entered by the tax agency. The taxpayer checks the figures and, if necessary, corrects errors and adds information or claims for deductions. Of the 7 million individual taxpayers who submitted income returns in 2003, $49 \%$

\footnotetext{
${ }^{4}$ More precisely, taxable wealth is calculated as $100 \%$ of the value of bank accounts paying interest above 100 SEK per year, bonds and fixed-income mutual funds, capital insurance products, residential real estate, and cars and boats exceeding 10,000 SEK in value, plus $80 \%$ of the value of A-list Swedish stocks, comparable foreign stocks, and equity mutual funds.
} 
just signed and returned the form, while another $51 \%$ changed or added information. ${ }^{5}$

We compiled the data supplied by Statistics Sweden into a panel covering four years (1999-2002) and the entire population of Sweden (about 9 million residents). The information available on each resident can be grouped into three main categories: 1) demographic characteristics; 2) disaggregated wealth portfolio; and 3) disaggregated income. We successively review these categories.

Demographic information includes age, gender, marital status, nationality, birthplace, education, and place of residence, as well as household composition and identification number. The household identification number allows us to group residents by living units and thus investigate finances at the family level. There are about 4.8 million households in Sweden during our sample period. Geographical data are coded with six digits that represent county, municipality, and parish; there are over 2200 separate parishes in the dataset.

The panel contains highly disaggregated wealth information, which lists the worldwide assets owned by the resident at the end of a tax year. All financial assets must be reported, including bank accounts, mutual funds and stocks. The information is provided for each individual account or each security referenced by its International Security Identification Number (ISIN). The database also records contributions made during the year to private pension savings, as well as debt outstanding at year end and interest paid during the year.

Income is reported both at the aggregate level and by individual source. For capital income, the database reports for each bank account or each security the income (interest, dividends) that has been earned and the sales that have taken place (number and price of sold securities) during the year. However the database does not report the exact date of a sale nor information on asset purchases. For labor income, the database reports gross labor income and business sector. The database also reports public and private pension income, military service compensation, and a detailed list of welfare transfers, including unemployment benefits, workers' compensation, paternity and maternity allowance, student allowance, housing allowance, and disability support.

We believe our data to be of unusually high quality as the information comes directly from Swedish firms, financial institutions and state agencies. The entire population is observed, so selection bias is not a problem. We acknowledge, however, four possible weaknesses in our dataset. First, we do not observe the value of households' defined contribution pension savings. These include assets in private pension plans and in the so-called premium portion of the public pension system. Second, we observe the total value of capital insurance products, a form of tax-favored saving, but we do not observe

\footnotetext{
${ }^{5}$ All tax returns are filed individually in Sweden, as the tax code does not allow the possibility of joint filing. When an asset is owned jointly, each household member is assigned for tax purposes a percentage of its value, which is reported in the dataset.
} 
the allocation of these assets. We have made several alternative assumptions about asset allocation in capital insurance and find that our results are robust to any of these assumptions. Third, bank accounts need not be reported to the Swedish Tax Agency unless they receive more than 100 SEK (or \$11) in interest during the year. We will discuss several imputation methods to address this problem of missing bank account data. Finally, there is the issue of tax evasion, which is probably more acute for wealthy households that own international assets. ${ }^{6}$

Sections 3-5 of the paper consist of a cross-sectional analysis for a random sample of 100,000 households, or slightly more than $2 \%$ of the Swedish population, at the end of 2002. This choice is motivated by computational convenience, and robustness checks confirm that our results are unaffected by changing the random subsample. We expect that econometric work based on the entire population would reduce the standard errors in our cross-sectional regressions by a factor of roughly seven. In Section 6, we investigate the behavior of the same households at the end of 1999 in order to explore possible changes in household behavior over time.

\section{Household Asset Allocation}

The goal of this section is to describe the asset allocation decisions of Swedish households. We begin by summarizing the aggregate properties of our sample, comparing them with other sources of aggregate data for Sweden. Then we examine household asset allocation and participation in the cross-section.

\subsection{Aggregate Statistics}

We report in Table 1 the aggregate wealth of households in our dataset and its breakdown into main asset categories at the end of 2002. Specifically, we compute gross wealth as the nominal value of financial and real estate assets held by the household. Aggregate gross wealth is approximately 479 billion dollars for the households in our

\footnotetext{
${ }^{6}$ We can cross-check the accuracy of foreign holdings in our dataset by comparing the cumulative sum of aggregate investment flows over a long time period. Since 1979, Statistics Sweden has reported two different measures of aggregate household investment: 1) the difference between aggregate disposable income and aggregate consumption (imputed from payroll, sales, tax and transfer data supplied by firms and government agencies); 2) the aggregate investment of individuals (reported by financial institutions). The cumulated difference between the first and the second estimates over the 1979-2002 period represents about $6.2 \%$ of the aggregate assets owned by households at the end of 2002 (see www.scb.se). The discrepancy is caused by a variety of items: a) the consumption of Swedish travelers in foreign countries; b) capital gains and c) unreported foreign investment. This analysis suggests that unreported foreign investments represent a modest fraction of household assets. This problem is probably only acute for the very rich, given the fixed costs associated with illegal foreign investments.
} 
dataset. On a per household basis, we estimate gross wealth at about $\$ 98,000$, debt at $\$ 30,000$, and therefore net wealth at $\$ 68,000$.

Financial wealth represents $27.5 \%$ of gross wealth, or about $\$ 27,000$ per household, while real estate accounts for the remaining $72.5 \%$. Financial wealth is decomposed into its main components: bank accounts, money market funds, mutual funds, stocks, capital insurance, and other assets (bonds and derivatives). Capital insurance is a form of investment subjected to a special tax treatment by the Swedish Tax Authority. It exists in two forms: unit link or traditional. Unit link savings are invested in mutual funds. Traditional insurance products guarantee a minimum fixed return, which could not exceed between 1999 and 2002 the $3 \%$ limit set by the Finance Inspection Board (Finansinspektionen). ${ }^{7}$

Cash, which consists of holdings in bank accounts and money market funds, represents $41 \%$ of financial wealth. Mutual funds and capital insurance account for $31 \%$, and individual securities (stocks, bonds and derivatives) for the remaining $28 \%$.

Individual stockholdings have a market value of 29.8 billion dollars in our dataset, and primarily consist of domestic equity (27.5 billion dollars). Since Swedish stock markets had a market capitalization of 201.4 billion dollars at the end of $2002,{ }^{8}$ the domestic investors in our dataset owned individually about $13.7 \%$ of Swedish stocks, a figure consistent with the $14.4 \%$ estimate reported by the Swedish central bank. ${ }^{9}$ Foreign stocks play a minor role with aggregate holdings of about 2.3 billion dollars. This finding is consistent with the relatively high cost of trading individual foreign stocks.

International diversification, however, is readily available to Swedish investors in the form of mutual funds. Swedish financial institutions have long recognized the importance of international diversification and routinely offer their customers a wide range of corresponding products. Some of these consist of international funds managed by domestic institutions, such as the Robur Bank's Euro Equity, or by leading Ameri-

\footnotetext{
${ }^{7}$ The taxation of capital insurance is based on the Statslåneränta, which is defined as the average market interest rate on Swedish government bonds with a remaining maturity of at least five years. Swedish authorities use the Statslåneränta as a proxy for the long-run nominal interest rate. Capital insurance accounts are subjected to a flat tax on their market value, whose rate is $27 \%$ of the Statslåneränta. In 2002 , this corresponded to a tax on market value that was slightly higher than $1 \%$.

${ }^{8}$ The main stockmarket is the Stockholm Stock Exchange (OMX), which had a market capitalization of 200.6 billion dollars at the end of 2002. Other markets include the Nya Marknaden (0.4 billion dollars), the Equities Market Place (0.1 billion dollars), and the Nordic Growth Market (0.3 billion dollars).

${ }^{9}$ In Table 1, domestic equity consists of all the publicly traded companies that are registered in Sweden. This definition excludes transnational companies, such as ABB or Astra Zeneca, which have important operations in Sweden, are traded in Swedish stockmarkets, and are included in the domestic indexes. When these companies are included in the definition of domestic equity, household direct investments in domestic stocks have an aggregate value of 263.9 billion SEK at the end of 2002, which represents $14.8 \%$ of Swedish stocks. The Central Bank estimate of direct domestic stockholdings $(14.4 \%)$ is thus contained between the low (13.7\%) and high (14.8\%) estimates from our dataset.
} 
can companies such as Fidelity, Goldman Sachs, J.P. Morgan or Merrill Lynch. These products are available at low cost and thus make it possible for middle-class Swedish households to achieve a good level of international diversification. We will investigate in Section 4 whether households take advantage of these opportunities.

Table 1 also includes the wealth statistics computed by Statistics Sweden (SCB). Our dataset matches these official statistics remarkably well. Statistics Sweden reports aggregate financial wealth equal to 1,165 billion SEK, which is very close to the 1,168.5 billion SEK in our sample. The aggregate estimates are also quite close for each category of assets. The main differences are for mutual funds and money market funds. We attribute this discrepancy to slightly different fund classifications. The aggregated holdings in both types of funds are 320 billion SEK with the SCB data, and 324.5 billion SEK with our data. ${ }^{10}$ Our dataset thus has good aggregation properties, which confirms its reliability and accuracy.

\subsection{Asset Allocation in the Cross-Section}

Aggregate statistics tell us how the average dollar of wealth is allocated. This can be quite different from the asset allocation of the average household, however, because the wealthy invest differently from poorer households (Tracy, Schneider and Chan 1999, Heaton and Lucas 2000, Carroll 2002). A detailed microeconomic analysis is required to obtain a good picture of investment patterns at the household level.

A good starting point is to plot the distribution of wealth in the population. Figure 1 reports the average value of gross and net wealth in different parts of the gross wealth distribution. The bottom $20 \%$ of households have almost no measured wealth (recall that small bank accounts are not recorded in our dataset), and so we omit them from the figure. The three lines in the figure represent gross wealth, financial assets, and net wealth. The lines diverge substantially for households in the middle of the wealth distribution, reflecting the fact that these households have a large fraction of their gross wealth in housing, and have correspondingly large mortgage debt. Sweden is a relatively egalitarian society by international standards, but even so wealthy households at the right of the figure have a disproportionate impact on aggregate asset allocation. ${ }^{11}$

In order to better assess the financial decisions of poorer households, we need to correct for the missing observation of some small bank accounts. In the rest of the

\footnotetext{
${ }^{10}$ We characterize a fund as money market if the standard deviation of its returns is less than $0.35 \%$ per year. This cutoff corresponds to a substantial gap in the distribution of historical standard deviations and a shift in the names of the funds.

${ }^{11}$ We can also see Swedish redistribution in action by comparing inequality in gross income (before taxes and transfers) with inequality in disposable income. For 2002 , we obtain $G=35.0 \%$ for gross income and $G=27.1 \%$ for disposable income. The value obtained for disposable income is consistent with the value $G=25.8 \%$ obtained by Statistics Sweden. These Gini coefficients are low by international standards.
} 
paper, we impute the balance of a bank account as a function of observable household characteristics, including financial wealth and education. The Appendix contains a full discussion of this methodology. Extensive checks show that our results are very robust to the choice (or absence) of imputation method.

Figure 2 illustrates the cross-sectional variation in the financial and real estate portfolio at the end of 2002. Panel A shows how portfolio composition varies with wealth. We subdivide households into wealth percentiles, and compute the average portfolio held by the members of each wealth group. Households in the lowest two deciles are not shown in the figure, because their total wealth is poorly measured and they hold almost nothing but cash. In the third and fourth deciles, households accumulate financial wealth in the form of cash, mutual funds, individual stocks and other financial assets. The share of real estate investments grows quickly with wealth for deciles in the middle of the wealth distribution. Households in the fifth to ninth percentile have about 60 to 80 percent of gross wealth invested in real estate and few risky financial assets. The share of real estate declines for households in the highest decile, while the share of risky financial assets rises quite substantially. The wealth composition of Swedish households is thus consistent with results reported for other industrialized countries such as the United States (Tracy, Schneider and Chan 1999, Bertaut and Starr-McCluer 2002).

In Panel B, we illustrate the variation of wealth composition with the age of the household head. ${ }^{12}$ The share of real estate rises for young households, peaks at $80 \%$ at the age of 40 , and then falls to about $50 \%$ for senior households. The share of mutual funds is stable around $10 \%$. The share of individual stocks is also relatively constant around $6 \%$, with slightly higher values for households in the younger age groups and in their fifties. The fraction of cash holdings is minimal for the middle-aged. It is presumably higher for young households who are saving to purchase their first home. The elderly tend to dissave, and their nominal cash holdings probably decrease less quickly than their other investments.

Thus in Sweden as in many other countries, there are four main groups of households: (1) households whose only savings are in the form of cash; (2) households who are saving for housing and are investing part of their wealth in mutual funds and stocks; (3) people with housing and few financial assets; and (4) households with large financial wealth.

Figure 3 illustrates cross-section variation in the financial portfolio, which of course excludes real estate. Figure $3 \mathrm{~A}$ shows how the composition of the financial portfolio varies with gross wealth. The shares of all risky assets increase quickly between the 20th and 30th percentile, and then become relatively stable until the 90th percentile. Mutual funds represent the largest fraction of risky assets held by households in this region of the wealth distribution. In the highest decile, however, direct stockholdings have a quickly increasing share and end up representing more than half of financial wealth. Thus while

\footnotetext{
${ }^{12}$ The household head is the member with the largest disposable income.
} 
stocks and mutual funds represent comparable fractions of aggregate wealth, Figure 3A illustrates that mutual funds dominate stocks in most household portfolios. Figure 3B illustrates that the composition of the financial portfolio is almost invariant with age. This finding is consistent with Ameriks and Zeldes (2004).

The investigation of household diversification must take into account the following two observations. First, the database contains the total value of capital insurance products but not the asset allocation within these products. We have checked that our diversification results are robust to reasonable variation in the assumptions we make about capital insurance. Second, while individual holdings of bonds and derivatives are observed in our dataset, they only account for a small share (about 5\%) of household portfolios. We simplify our analysis by excluding these assets from all the calculations that follow. This approach is motivated by the fact that the asset pricing models used in Section 4 do not apply well to bonds and derivatives. Furthermore, the contribution of bonds to portfolio risk depends on the household's investment horizon, which we do not observe, since bonds can be viewed as safe assets for long-term investors (Campbell and Viceira 2002).

For each household, we consider three types of financial portfolios: the complete portfolio, which contains all the stocks, mutual funds and cash owned by the household; the risky portfolio, which contains stocks and mutual funds but excludes cash; and the stock portfolio, which contains direct stockholdings but excludes equity owned through mutual funds. The complete portfolio tells us the overall amount of risk taken by the household; the risky portfolio allows us to decompose the risk the household takes; and the stock portfolio allows us to compare our results with those of Goetzmann and Kumar (2004), who observe only directly held stocks and not mutual funds. We find that $87 \%$ of participating households own mutual funds, while $55 \%$ are direct stockholders. Furthermore, $76 \%$ of direct stockholders also own mutual funds. These facts imply that mutual funds play a key role in household diversification.

In Table 2, we report summary statistics for these portfolios as well as other household characteristics. A household is viewed as a participant in risky asset markets if its risky portfolio share is positive. A participating household takes financial risk and can make diversification mistakes. Average financial wealth is substantially higher for participants $(\$ 42,000)$ than nonparticipants $(\$ 8,000)$. We also observe that for participants, the average value of the complete portfolio is about $\$ 36,000$ as compared to the $\$ 42,000$ for an average financial portfolio (which includes capital insurance, bonds and derivatives). 


\subsection{Who Participates in Risky Asset Markets?}

We next investigate the decision to participate in risky asset markets. At the end of $2002,62 \%$ of Swedish households were participants. As in earlier research (e.g. VissingJorgensen 2002a,b), the dataset allows us to investigate the correlation between participation and other household characteristics. In Table 3, we report the results of a probit regression. The estimates show that a household is more likely to participate if it has higher income, higher financial or real estate wealth, higher liabilities or is more educated. Participation also tends to be higher for retirees and investors with large contributions to a private pension plan relative to disposable income. Variables negatively related to participation include age, household size, unemployment and immigration. Entrepreneurship has no significant effect. ${ }^{13}$ These findings are consistent with the assumption that risky investments require fixed learning and setup costs, which may be smaller for more educated and sophisticated households and which are worth paying only if financial asset holdings are sufficiently large.

We determine the relative importance of these variables by considering a reference household that is assigned the average of all continuous characteristics and zero values for all dummy variables. We then examine one-by-one the marginal effect of each predicting variable. The third column of the probit regression reports the impact of increasing a continuous regressor by one standard deviation, or of setting a dummy variable to one. We observe that financial wealth has the strongest impact on participation, increasing its probability by more than $20 \%$. Disposable income, age, education, immigration and the share of private pensions also have substantial effects in excess of $5 \%$.

We next ask whether the same observable characteristics predict the share of financial wealth invested in risky assets, conditional on participation. As shown in the fourth and fifth columns of Table 3, most predictors of participation do not help explain the risky share. This finding is consistent with earlier studies (e.g. Ameriks and Zeldes 2004) showing that the average share of participating households is quite stable, and in particular varies little with age. However the risky share is substantially higher for households with higher financial wealth, an effect emphasized by Carroll (2002). Household size and entrepreneurship have a clear negative impact. These effects are consistent with the intuition that individuals with more background risk, whether in the form of entrepreneurial risk or random family needs, tend to reduce their exposure to risky financial assets.

\footnotetext{
${ }^{13}$ The entrepreneur dummy equals 1 if the household head works at least part-time for her own business.
} 


\section{Household Diversification}

We now ask how households take risk, and specifically whether they choose meanvariance efficient portfolios. Our analysis of household diversification abstracts away from labor income, human capital and real estate considerations. This approach has the advantage of comparing actual household decisions with the simplest and most widely known precepts of financial theory. Moreover, empirical evidence suggests that households do not hedge labor income risk (Massa and Simonov 2003), and we thus focus in this paper on the more elementary problem of financial portfolio diversification. Similarly, real estate can be viewed as a hedge against future rental costs (Flavin and Yamashita 2002, Sinai and Souleles 2005), and it is therefore unclear whether it should be included in the analysis of household risk. A more detailed investigation of these issues is left for future research.

\subsection{Idiosyncratic and Systematic Risk}

We observe at the end of year $t$ the portfolio of financial assets owned by household $h$. Let $\boldsymbol{\omega}_{h}$ denote the corresponding vector of portfolio weights. The portfolio generates a random return between the end of year $t$ and the next time the portfolio is rebalanced. Since the endogenous decision to rebalance is unobserved in our yearly dataset, we cannot directly compute household portfolio returns. For this reason, we investigate the properties of household portfolios by estimating the moments of asset returns and then inferring the household portfolio characteristics. For instance, we estimate the variancecovariance matrix $\boldsymbol{\Sigma}$ of asset excess returns and then impute the variance $\sigma_{h}^{2}=\boldsymbol{\omega}_{h}^{\prime} \boldsymbol{\Sigma} \boldsymbol{\omega}_{h}$ of individual portfolios. Wermers (2000) has used a similar method to evaluate the properties of stock portfolios held by mutual funds.

We begin by presenting results that impose no restriction on the mean returns of financial assets. Excess returns are computed for all assets as monthly returns in local currency in excess of the yield on the one month Swedish T-bill. The variance-covariance matrix $\boldsymbol{\Sigma}$ is estimated by the sample covariance matrix of the $N$ assets. We present in Table 4 the characteristics of the risky portfolios owned by households at the end of 2002. The focus on risky portfolios allows us to investigate diversification choices while controlling for differences in cash holdings. The cross-sectional distribution of the standard deviation $\sigma_{h}$ is reported in the first column. The total risk $\sigma_{h}$ has a median value of $20.7 \%$ per year and a 75 th percentile equal to $25.8 \%$. Most households thus select risky portfolios with moderate standard deviations. A sizeable fraction of households, however, select risky portfolios with high $\sigma_{h}$, such as $37.0 \%$ (90th percentile) or $69.6 \%$ (99th percentile).

We compare these results to a diversified stock benchmark. Because Sweden is a small and open economy, it is natural to consider a diversified portfolio of global stocks. 
We choose the All Country World Index (henceforth "world index") compiled by Morgan Stanley Capital International (MSCI). Because the world index is denominated in US dollars, we must analyze currency risk to Swedish households. Specifically, the domestic excess return on an asset is the difference between its return in SEK and the Swedish Treasury bill rate. Consider a Swedish investor who purchases the index and fully hedges the currency risk on the futures market. Under covered interest parity, the corresponding excess return in SEK equals the excess dollar return on the index over the US Treasury bill rate. ${ }^{14}$ For this reason, "world index in USD" will henceforth refer to a hedged investment in the global portfolio, and "world index in SEK" to its unhedged equivalent. Over the 1983-2004 period, the MSCI world index in USD has a mean excess return of $6.7 \%$ and a mean standard deviation of $14.7 \%$, that is, a Sharpe ratio of $45.2 \%$.

Given a benchmark index or asset $B$, we consider the return decomposition

$$
r_{h, t}^{e}=\alpha_{h}+\beta_{h} r_{B, t}^{e}+\varepsilon_{h, t}
$$

where $r_{h, t}^{e}$ and $r_{B, t}^{e}$ respectively denote the domestic excess returns on the household portfolio and on the benchmark. ${ }^{15}$ Note that the decomposition is purely statistical and does not assume an asset pricing model. We infer the variance decomposition

$$
\sigma_{h}^{2}=\beta_{h}^{2} \sigma_{B}^{2}+\sigma_{i, h}^{2}
$$

The household portfolio thus has systematic risk $\left|\beta_{h}\right| \sigma_{B}$, and idiosyncratic risk $\sigma_{i, h}$.

We report in Table 4 how the decomposition of a household's risky portfolio varies with its overall standard deviation $\sigma_{h}$. Specifically, we consider 100 households around each percentile of $\sigma_{h}$ and compute the average risk characteristics of these households. For the median $\sigma_{h}=20.7 \%$, systematic risk has a median of $13.6 \%$ and idiosyncratic risk a median of $15.6 \%$. Idiosyncratic risk is thus a large determinant of the household risk exposure. The idiosyncratic variance share

$$
\frac{\sigma_{i, h}^{2}}{\sigma_{h}^{2}}=\frac{\sigma_{i, h}^{2}}{\beta_{h}^{2} \sigma_{B}^{2}+\sigma_{i, h}^{2}}
$$

has a median value of $56.7 \%$. More than half the risk borne by a median household in its risky portfolio is uncorrelated with the benchmark. This risk would be unrewarded in a CAPM-type setting. We further note that the idiosyncratic variance share tends to increase with $\sigma_{h}$. Households with very high $\sigma_{h}$ bear a large fraction of idiosyncratic risk in their portfolios.

\footnotetext{
${ }^{14}$ See the Appendix for further discussion. Solnik and McLeavy (2003) provide a textbook treatment of currency risk and hedging.

${ }^{15}$ The variance covariance matrix $\boldsymbol{\Sigma}$ allows us to estimate the beta coefficients $\boldsymbol{\beta}$ of the assets, and thus of the household: $\beta_{h}=\boldsymbol{\omega}_{h}^{\prime} \boldsymbol{\beta}$.
} 
The median value of $\beta_{h}$ is slightly lower than 1 for households with median exposure $\sigma_{h}$. We observe that the betas of household portfolios grow monotonically with $\sigma_{h}$. The relation between $\sigma_{h}$ and $\beta_{h}$ is illustrated by the scatter plot in Figure 4 . The solid line represents $\left|\beta_{h}\right| \sigma_{B}$, which is by (4.1) the theoretical lower bound of $\sigma_{h}$ for a given level of $\beta_{h}$. Households are almost all located away from the theoretical lower bound defined by the hedged world index, but tend to cluster in the region around the unhedged world index and the Swedish domestic index.

An alternative benchmark for observed portfolios is the value-weighted index of all stocks and mutual funds held by Swedish households. We compute the wealthweighted portfolio of our total set of investors, $w_{\text {pop }}$, which generates excess return $r_{\text {pop }}$. The standard deviation

$$
\sigma\left(r_{h}-r_{p o p}\right)
$$

quantifies the risk that households bear by holding their observed portfolios rather than pooling their assets in a single common mutual fund. We observe that the median value of $\sigma\left(r_{h}-r_{\text {pop }}\right)$ is $7.3 \%$, and is a U-shaped function of $\sigma_{h}$.

\subsection{Contributors to Idiosyncratic Risk}

We next analyze the idiosyncratic volatility of a household risky portfolio. Consistent with previous notation, let $\varepsilon_{h, t}$ denote the regression residual of the portfolio on the benchmark. We have $\varepsilon_{h, t}=\sum_{n=1}^{N} \omega_{n, h} \varepsilon_{n, t}$, where $\varepsilon_{n, t}$ is the residual in a regression of asset $n$ on the benchmark. We consider a stylized symmetrical model in which the residuals of all assets in a household's portfolio have the same variance $\sigma_{a, h}^{2}$ and the same correlation $\rho_{a, h}$ with each other. It is straightforward to show that the variance of the portfolio idiosyncratic component satisfies

$$
\sigma_{i, h}^{2}=\sigma_{a, h}^{2}\left[C_{a, h}+\left(1-C_{a, h}\right) \rho_{a, h}\right],
$$

where $C_{a, h}=\sum_{n=1}^{N} \omega_{n, h}^{2}$ is a measure of the concentration of the portfolio. Let $\bar{c}_{a}$ denote the average value of $\ln C_{a, h}$ in the population, and $\bar{C}_{a}=\exp \left(\bar{c}_{a}\right)$. A loglinearization of (4.2) around $\rho=0$ and $c=\bar{c}_{a}$ implies

$$
\ln \left(\sigma_{i, h}\right) \approx \ln \left(\sigma_{a, h}\right)+\frac{1}{2} \ln \left(C_{a, h}\right)+\frac{1}{2}\left(\frac{1}{\bar{C}_{a}}-1\right) \rho_{a, h}
$$

This decomposition suggests that we should relate log idiosyncratic portfolio standard deviation to the $\log$ of the average idiosyncratic standard deviation of assets in the portfolio, the log concentration in the portfolio, and the average correlation across assets in the portfolio. We can ask whether households that take a lot of idiosyncratic risk typically do so a) by picking volatile assets, b) by holding a concentrated portfolio, or c) by picking correlated assets. 
This decomposition treats all assets in the risky portfolio equally, whether they are stocks or mutual funds. An alternative approach is to assume that mutual funds are fully diversified. Let $D_{h}$ denote the share of stocks directly held in the risky portfolio, and let $C_{s, h}$ denote the concentration of the stock portion of the portfolio. We can show that

$$
\ln \left(\sigma_{i, h}\right) \approx \ln \left(D_{h}\right)+\ln \left(\sigma_{s, h}\right)+\frac{1}{2} \ln \left(C_{s, h}\right)+\frac{1}{2}\left(\frac{1}{\bar{C}_{s}}-1\right) \rho_{s, h} .
$$

The alternative decomposition attributes idiosyncratic risk to a) a high share of stocks rather than mutual funds in the portfolio; b) volatile stocks; c) a concentrated stock portfolio; and d) correlated stocks.

Table 5 presents a simple empirical analysis of these two decompositions. The top panel treats all assets symmetrically. The cross-sectional $R^{2}$ of the decomposition (4.3) is $98 \%$. Portfolios are sorted by their idiosyncratic risk, and 1000 households are examined around each percentile of the idiosyncratic risk distribution. The first column reports idiosyncratic risk, the second column reports the average idiosyncratic volatility of individual assets in the portfolio, the third column reports the concentration of the portfolio, and the fourth column reports the average correlation of assets in the portfolio. The main influence on idiosyncratic volatility is clearly the average idiosyncratic volatility of the assets in the portfolio, which increases monotonically with idiosyncratic risk. Concentration is U-shaped, while asset correlation is hump-shaped. These results reflect the fact that households with low idiosyncratic risk often hold concentrated portfolios of mutual funds, while households with high idiosyncratic risk hold concentrated portfolios of individual stocks. In the middle of the idiosyncratic risk distribution, households hold diversified portfolios of mutual funds and stocks which may tend to be more correlated with one another. In support of this interpretation, the far right column of the table shows that the stock share increases with idiosyncratic risk.

The bottom panel of Table 5 treats mutual funds as perfectly diversified. The crosssectional $R^{2}$ of the decomposition (4.4) then falls to $71 \%$. Stockholding households only are sorted by their idiosyncratic risk. The remaining columns show the stock share, average idiosyncratic volatility of stocks in the portfolio, concentration of the stock portfolio, and average correlation of stocks in the portfolio. The main influence on idiosyncratic risk is the share of individual stocks as opposed to mutual funds. At the right tail of the risk distribution, the choice of highly volatile individual stocks also has an effect. Concentration is U-shaped; some households with low idiosyncratic risk have a very small share of their wealth in one or two stocks, while households with high idiosyncratic risk have a large share of their wealth in one or two stocks. Intermediate households are more likely to hold diversified portfolios of individual stocks. Correlation across stocks in the portfolio shows little variation across households.

These results show that in order to assess diversification at the household level, it is 
essential to observe holdings of mutual funds. The concentration of the stock portfolio, a statistic emphasized by Blume and Friend (1975) and Kelly (1995), is meaningless without a complete picture of the remaining constituents of the portfolio.

\subsection{Estimating the Mean Returns of Household Portfolios}

Since expected asset returns are difficult to estimate, we follow the tradition of inferring the mean return vector $\boldsymbol{\mu}$ from asset pricing models. We assume that assets are priced on world markets in an international currency, specifically, that the CAPM holds in dollar-denominated excess returns relative to the US Treasury bill:

$$
r_{j, t}^{e}=\beta_{j} r_{m, t}^{e}+\varepsilon_{j, t}
$$

The market return $r_{m, t}^{e}$ is measured as the US dollar return of the world index in excess of the US T-bill. We show in the Appendix how to conduct mean-variance analysis in Swedish kronas. Under covered interest rate parity, $r_{m, t}^{e}$ coincides with the excess return (in domestic currency) of the fully hedged version of the index relative to the Swedish T-bill. In particular, the hedged index is mean-variance efficient from the perspective of a domestic investor.

As a robustness check, we also consider the dollar-denominated three-factor Fama and French (1993) model:

$$
r_{j, t}^{e}=\beta_{j} r_{m, t}^{e}+\gamma_{j} S M B_{t}+\delta_{j} H M L_{t}+\varepsilon_{j, t},
$$

where $S M B$ and $H M L$ are the US size and value factors obtained from Ken French's website.

The universe of assets consists of all the stocks and mutual funds owned by Swedish households in our panel. ${ }^{16}$ We estimate each asset pricing model over the period 19832004 and then infer $\boldsymbol{\mu}$, given $\boldsymbol{\Sigma}$, using standard procedures summarized in the Appendix.

We use the estimated moments of individual asset returns to calculate the means and variances of household portfolio returns. For each household, the dataset contains holdings at the security level and the balances of bank accounts. The risk free rate in Sweden is again proxied by the yield on the one-month Swedish T-bill. Since the spread between the risk-free rate and the yield on bank deposits can be considered as a compensation for bank services, bank balances are assumed to earn the risk-free rate. The same assumption is extended to money market funds and verified empirically.

We report in Figure 5 a scatter plot of household portfolios in the mean-standard deviation plane. In order to produce a clear picture, we plot a subsample of 10,000

\footnotetext{
${ }^{16}$ Since the factors used in the CAPM and Fama-French models are stock portfolios, these models may not be suitable for estimating the average returns on bond funds. We check in unreported work that our results are robust to the treatment of bond funds.
} 
randomly selected households. Panel A shows the risk characteristics of households' stock portfolios, which appear quite inefficient as found by Goetzmann and Kumar (2004). Panel B includes households' cash and mutual fund holdings and presents a more optimistic view of households' risk management. Households appear much better diversified when we include their holdings of mutual funds and scale their risky asset holdings by their total financial assets rather than merely their stockholdings.

We report in Table 6 the most widely held stocks and mutual funds in our entire database. For individual stocks (Panel A), we eliminate households that hold more than $\$ 5$ million in a single stock. This procedure filters out large insider holdings and enables us to focus on "popular stocks". For each company, the columns of Panel A report respectively: (1) the dollar value of direct holdings; (2) the company's weight in the aggregate value of household direct stockholdings; (3) the fraction of direct investors who own at least one share of the company; (4) the fraction of the company's market capitalization that is directly held by households; (5) the company's value-weighted share of the Swedish stockmarket; (6) the stock's Sharpe ratio estimated with the dollar CAPM.

The telecommunications company Ericsson is the most widely held stock in Sweden. It is directly owned by almost half of direct investors and its share of direct investments is large (18.9\%) relative to market cap. Other popular stocks are fashion companies (Hennes and Mauritz), telecommunications companies (Telia Sonera), paper manufacturers (Svenska Cellulosa), pharmaceuticals (Astra Zeneca and Pharmacia), and banks (SEB, SHB, Förenings Savings Bank). There is also a Finnish stock (Nokia). We note that these stocks are well-known household names, often with relatively low Sharpe ratios. The table is thus consistent with the familiarity motive for direct stock investment proposed by Huberman (2001) and others.

In Panel B of Table 6 we report the ten most widely held mutual funds. These funds are characterized by considerably higher Sharpe ratios on the order of $30 \%$. They are sold by a few large banks: the aforementioned SEB, SHB, and FSB, along with Nordea. Panel $\mathrm{C}$ reports the composition of these ten mutual funds. We note that most of them are internationally diversified. With the exception of SEB Sverige, each fund holds more than $25 \%$ of its assets in international securities. The most widely held fund (FSB/Robur Kapitalinvest) contains $54 \%$ of international stocks, while the second most popular fund (Nordea Futura) holds 17\% in foreign stocks and 33\% in foreign bonds. These numbers suggest that popular mutual funds enable Swedish households to achieve reasonable levels of international diversification. None of these funds, however, hedges for currency risk. It is thus considerably easier for Swedish households to hold portfolios with the efficiency of the unhedged world index than to hold portfolios that are comparable to the hedged world index. 


\subsection{Mean-Variance Measures of Diversification}

We now provide a detailed quantitative assessment of the losses due to suboptimal diversification. The moments of all assets and portfolios are based on the dollar asset pricing models (4.5) and (4.6) described in the previous subsection.

Relative Sharpe Ratio Loss. Diversification losses can be computed by comparing the Sharpe ratio of a household portfolio to the Sharpe ratio of a benchmark index $S_{B}$. The benchmark need not necessarily be efficient, so that under the CAPM $S_{B}$ can differ from the maximum Sharpe ratio $S_{m}$ of the market portfolio. For every household $h$, we denote by $\mu_{h}$ and $\sigma_{h}$ the mean and standard deviation of the excess return on the risky portfolio, and by

$$
S_{h}=\frac{\mu_{h}}{\sigma_{h}}
$$

the corresponding Sharpe ratio. Of course, the Sharpe ratio on the household's complete portfolio is also $S_{h}$. The loss from imperfect diversification with respect to the benchmark can be quantified by the relative Sharpe ratio loss:

$$
R S R L_{h}=1-\frac{S_{h}}{S_{B}} .
$$

In Table 7, we consider four indexes for the benchmark Sharpe ratio $S_{B}: 1$ ) the world index in USD; 2) the world index in SEK; 3) a krona-denominated index of the domestic stock market (MSCI Sweden Equity); and 4) the highest Sharpe ratio achieved by any household portfolio in our sample. Under the CAPM, the benchmark Sharpe ratio $S_{B}$ increases from $27.4 \%$ for the Swedish index to $45.2 \%$ for the hedged world index, which is mean-variance efficient by construction. The world index in SEK has an intermediate Sharpe ratio equal to $34.6 \%$; this illustrates that the inefficiency of the Swedish index is due to both currency risk and suboptimal concentration in national stocks. The most efficient household in our sample has a Sharpe ratio of $40.6 \%$, somewhat lower than the theoretically achievable maximum.

The Fama-French asset pricing model provides analogous results. The hedged world index has by design the same Sharpe ratio as under the CAPM. The CAPM and FF provide very similar estimates for the Swedish index and the world index in SEK. The highest Sharpe ratio achieved by a household is $45.5 \%$, which is slightly higher than the $45.2 \%$ value reported for the hedged world index. Thus, while FF offers the possibility of outperforming the hedged world index, the gains achieved by households are quite limited in practice.

When the benchmark portfolio used to calculate the relative Sharpe ratio is meanvariance efficient, as in the case of the hedged world index in the dollar CAPM, the relative Sharpe ratio loss is a nonlinear transformation of the share of idiosyncratic 
variance we reported in Table 4 . The relation is

$$
\left(1-R S R L_{h}\right)^{2}=1-\frac{\sigma_{i, h}^{2}}{\sigma_{h}^{2}} .
$$

Thus a high share of idiosyncratic variance, as found in Table 4, implies a high relative Sharpe ratio loss with respect to the mean-variance efficient index. ${ }^{17}$

Table 7 reports the cross-sectional distribution of the relative Sharpe ratio loss in our sample of Swedish households. The top panel looks at complete household portfolios (equivalently, risky household portfolios), while the bottom panel looks at stock portfolios for comparison with previous work. The columns are grouped in pairs, assuming the CAPM and Fama-French model respectively. The first pair of columns uses the hedged world index as the benchmark; the next pair of columns uses the unhedged world index; the third pair uses the Swedish index; and the final pair uses the household portfolio in our sample that has the highest Sharpe ratio.

For complete portfolios, the median household has a relative Sharpe ratio loss of $35 \%$ with respect to the hedged world index under the assumption that the dollar CAPM holds, and a slightly smaller loss of $32 \%$ if the Fama-French model holds. This difference implies that Swedish household portfolios have a slight tilt towards small stocks and value stocks, relative to the world index, which improves their returns slightly in the Fama-French model. ${ }^{18}$ The relative Sharpe ratio loss is smaller, at $14 \%$ (14\%) with respect to the unhedged world index. Relative to the Swedish index, the median Swedish household actually has a negative relative Sharpe ratio loss of $-8 \%(0 \%)$, indicating that Swedish households are sufficiently diversified internationally to outperform their own domestic stock index. Finally, the relative Sharpe ratio loss with respect to the bestperforming household in our sample is analogous to the results with respect to the hedged world index.

These results are consistent with the fact that the portfolios of many Swedish households contain a large fraction of international investments and mutual funds. Median losses are relatively limited compared to the unhedged world index, but quite substantial compared to its hedged version. This is a sensible finding since unhedged international securities and equity funds are widely available to individual investors, as we saw in

${ }^{17}$ More generally, the relative Sharpe ratio loss with respect to an arbitrary benchmark $B$ satisfies

$$
\left(1-R S R L_{h}\right)^{2}=\left(1-\frac{\sigma_{i, h}^{2}}{\sigma_{h}^{2}}\right) /\left(1-\frac{\sigma_{i, B}^{2}}{\sigma_{B}^{2}}\right),
$$

where $\sigma_{i, h}$ and $\sigma_{i, B}$ denote idiosyncratic risk relative to the efficient index.

${ }^{18}$ We verify this intuition by computing the loadings of individual households on the size and value factors. The size loading is positive for about $90 \%$ of households, and its cross-sectional median and mean are both equal to 0.23 . Similarly, the value loading is positive for about $80 \%$ of households, and its cross-sectional median and mean are 0.08 and 0.10 respectively. 
Table 6, while currency-hedged investments are less common. Wider availability of currency-hedged hedged global equity funds might further improve international diversification of Swedish portfolios.

The importance of mutual funds is underscored by the fact that in the bottom panel of Table 7 we report substantially higher losses with stock portfolios. In particular, while the complete portfolio tends to outperform the national stock market, the stock portfolio tends to underperform it. A dataset containing only direct stock holdings might lead us to conclude that households underperform the domestic equity market; when mutual funds are observed, however, we see that the results are reversed.

Finally, the table reveals large heterogeneity in the losses incurred by households. For example, $5 \%$ of households have Sharpe ratios below one-third the level of the hedged world index. While a large fraction of households thus seem to achieve a fairly reasonable level of performance, especially when compared to readily available indexes such as the Swedish or unhedged world index, a non-trivial fraction of the population seems to invest in a highly inefficient manner.

Return Loss. The relative Sharpe ratio loss quantifies the diversification level achieved by a risky portfolio. For complete portfolios, however, this statistic provides only limited information on overall efficiency. Consider for instance an investor who allocates a small fraction of his wealth to a single stock, and invests the rest in the riskless asset. The relative Sharpe ratio loss reveals the inefficiency of the risky portfolio, but the investor might in fact be very close to the mean-variance frontier. This is an important example, since Table 5B shows that some investors own only one or two individual stocks, giving them a high concentration $C_{s, h}$ in the decomposition (4.4), but invest only a small fraction of their wealth in these stocks, giving them a low $D_{h}$ which offsets the effect of concentration.

Accordingly we consider the following alternative measure. The return loss is the average return lost by the investor by choosing a suboptimal portfolio at her chosen risk level:

$$
R L_{h}=w_{h}\left(S_{B} \sigma_{h}-\mu_{h}\right),
$$

where $w_{h}$ denotes the portfolio's weight in risky assets. In the mean-standard deviation plane, the return loss is the vertical distance between the household portfolio and the efficient frontier.

In Table 8, panel A, we report return losses for households' complete portfolios (setting $w_{h}$ equal to the share of the risky portfolio in the complete portfolio) and for their risky portfolios (setting $w_{h}$ equal to one). The median return loss on the complete portfolio with respect to the hedged world index is $1.17 \%$ if the CAPM holds, and $1.04 \%$ if the Fama-French model holds. The median return loss is smaller with respect to the unhedged world index at $0.30 \%(0.29 \%)$, and negative with respect to the Swedish index 
at $-0.11 \%(0.00 \%)$. Median losses are about three times larger, in absolute value, for risky portfolios than for complete portfolios. This is consistent with the large share of Swedish household wealth held in riskless assets.

As with Sharpe ratios, we observe considerable heterogeneity in return losses. The costs of underdiversification are modest for a majority of investors but are substantial for a sizeable minority. For instance, under the CAPM, almost $5 \%$ of investors have return losses on their complete portfolios of $5 \%$ per year or more.

One explanation for return losses might be that households are unable to leverage the market portfolio (Black 1972). A risk-tolerant household might rationally select an inefficient portfolio of high-beta stocks in order to obtain a higher expected return than is available by holding the unleveraged market portfolio. We check that only $3.7 \%$ of complete portfolios have a beta larger than one, a necessary condition to be justified by this constraint. In unreported work, we have reestimated the distribution of losses on the subset of households with a beta less than one, and have found very little difference. Thus, borrowing constraints seem to have little effect on the reported loss distribution.

Another concern with the losses in Table $8 \mathrm{~A}$ is that they measure underdiversification costs in return units; that is, they measure costs relative to the size of an investor's portfolio. If an investor has only a very small portfolio, the implied cost in dollars or as a fraction of income may be negligible. To address this concern, in panel B of Table 8 we report return losses in dollars per year and as a fraction of disposable income (measured as an average over three years to reduce the influence of temporary fluctuations). We see that the median cost of underdiversification is only $\$ 131$ per year under the CAPM ( $\$ 118$ under the Fama-French model) with respect to the hedged world index, and $\$ 33$ per year $(\$ 30)$ with respect to the unhedged world index. However the distribution of dollar costs has a fat right tail. The 90th percentile is $\$ 1,190(\$ 1,039)$ with respect to the hedged world index, and there are some large dollar numbers in the top decile resulting from large undiversified Swedish portfolios. Similarly, when we scale by disposable income we find that the median return loss is only $0.51 \%(0.46 \%)$ of disposable income, but the 90 th percentile is $4.48 \%$ (3.94\%) of disposable income. Some extremely high numbers in the far right tail of this distribution result from disposable income close to zero.

Connecting the Dots. We now summarize how the various results fit together. The risky portfolio of a participating household has a median value of $\$ 4,372$ (Table 2) and a median $\beta_{h}$ equal to 0.92 (Table 4 ). Since the risk premium on the global equity index is about $6.7 \%$, the median participating household earns an excess payoff of $\$ 4,372 \times 6.7 \% \times$ 0.92 or $\$ 269$ per year compared to a pure cash investment. In Table 4 , we observe that $56.7 \%$ of the risk born by the median household is idiosyncratic and thus unrewarded. The corresponding Sharpe ratio loss RSRL is by (4.7) equal to $34.2 \%$, which matches 
quite closely the estimate reported in Table 7 . Since the median volatility $\sigma_{h}$ of the risky portfolio is $20.7 \%$ (Table 4) and the Sharpe ratio of the currency-hedged world index is $45.2 \%$, we infer that the median return loss is $45.2 \% \times 20.7 \% \times 34.2 \%$ or $3.21 \%$, which is consistent with Table $8 \mathrm{~A} .{ }^{19}$ The median dollar loss from suboptimal diversification should thus be $\$ 4,372 \times 3.21 \%=\$ 140$, which is close to the $\$ 131$ estimate reported in Table 8B.

Thus, by choosing an underdiversified portfolio, the median household earns a risk premium of about $\$ 269$ per year on its risky portfolio worth $\$ 4,372$ instead of the $\$ 409$ that it could earn by picking an efficient portfolio with the same volatility. While this description characterizes a large fraction of the population, we also find that some investors make very poor choices and incur much larger losses.

\subsection{Utility Loss from Underdiversification}

We now propose a simple utility loss calculation to measure the overall economic cost of household underdiversification.

Principle. Consider a household with an infinite horizon, CRRA utility of consumption with discount factor $\delta$ and risk aversion $\gamma$ :

$$
E_{0} \sum_{t=0}^{\infty} \delta^{t} \frac{C_{t}^{1-\gamma}}{1-\gamma}
$$

The household is able to invest in two assets: a safe asset with $\log$ return $r_{f}$, and a risky asset with $\log$ return $r_{t+1}$ distributed i.i.d. normal. Let $\sigma$ denote the standard deviation of the risky asset, and $S$ its Sharpe ratio.

The household's investment problem consists of choosing the optimal portfolio share in the risky asset, $w$, and the optimal consumption-wealth ratio. We show in the Appendix the standard result that

$$
w=\frac{S}{\gamma \sigma} .
$$

The optimal consumption-wealth ratio is fully determined by

$$
\left(1-\frac{1}{\gamma}\right)\left(r_{f}+\frac{1}{2} \frac{S^{2}}{\gamma}\right)-\frac{\ln (\delta)}{\gamma}
$$

Financial opportunities $\left(r_{f}\right.$ and $S$ ) thus impact household utility through the choice of the consumption-wealth ratio.

This gives us all the ingredients we need to analyze the welfare effect of a change in Sharpe ratios. We consider a household $h$ with risk aversion $\gamma_{h}$ and observed Sharpe

\footnotetext{
${ }^{19}$ The return loss is $\left(S_{m}-S_{h}\right) \sigma_{h}$, or equivalently $R L_{h}=S_{m} \sigma_{h} R S R L_{h}$.
} 
ratio $S_{h}$. If the household adopts instead the Sharpe ratio $S_{B}$ of a benchmark, the effect on utility is equivalent to an increase in the riskless interest rate of

$$
U L_{h}=\frac{S_{B}^{2}-S_{h}^{2}}{2 \gamma_{h}}
$$

The utility loss increases with the inefficiency of the household portfolio, $S_{B}^{2}-S_{h}^{2}$, and decreases with household risk aversion $\gamma_{h}$.

Estimates of Utility Loss. While the Sharpe ratios in (4.9) are easily measured, the selection of $\gamma_{h}$ must be addressed. Since an investor's portfolio is in principle informative on her risk-aversion, we find it sensible to impute $\gamma_{h}$ from the observed portfolio of risky assets. For this reason, assume that the investor correctly perceives the Sharpe ratio $S_{h}$ of her complete portfolio but is unaware of the benchmark Sharpe ratio $S_{B}$. We then infer from (4.8) that the coefficient of relative risk aversion satisfies

$$
\gamma_{h}=S_{h} /\left(w_{h} \sigma_{h}\right)
$$

where $\sigma_{h}$ is the standard deviation of the risky portfolio. This relation provides an estimate of the risk aversion of each household. It is easy to check that with the efficient benchmark, the inferred utility loss $U L_{h}$ is necessarily larger than the return loss $R L_{h}$ (the increase in expected return at a constant standard deviation) of the complete portfolio. This because households incur two types of losses: (1) they do not choose the highest-yielding portfolio given their risk level; and (2) they choose a suboptimal level of risk because they are unduly pessimistic about the optimal Sharpe ratio.

We report the estimates in Table 9. The median utility loss is equivalent to a decline in the riskless interest rate of $1.52 \%$ under the CAPM and $1.32 \%$ under the Fama-French model compared to the hedged world index. The median utility loss is thus relatively modest, and only slightly larger than the return loss reported in Table 8 . The right tail of the utility loss distribution is, however, even fatter than the right tail of the return loss distribution, because the difference between the utility loss and return loss increases when these losses are large. To understand the magnitude of these losses, the middle panel of Table 9 reports them in dollars per year, and the bottom panel expresses them as a fraction of disposable income. $5 \%$ of households incur utility losses greater than $\$ 3000$ per year or $10 \%$ of their disposable income, relative to the hedged world index. Relative to the unhedged world index, the losses are only one-third as large, but are still substantial.

These results depend of course on the assumption we have made about risk aversion. To see how sensitive our results are to the choice of $\gamma$, we can compute utility losses for a range of possible $\gamma$ for a typical investor with a relative Sharpe ratio loss of $35 \%$. Relative to the hedged world index, we find that risk aversion of 2 gives a utility loss of 
$2.95 \%$. The utility loss falls to $1.97 \%$ for risk aversion of $3,1.48 \%$ for risk aversion of $4,1.18 \%$ for risk aversion of $5,0.98 \%$ for risk aversion of 6 , and $0.84 \%$ for risk aversion of 7 . The median utility loss reported in Table 9 roughly coincides with a calibrated value of $\gamma$ between 4 and 6 . Thus our results in Table 9 do not depend on extreme assumptions about risk aversion.

Mutual Fund Fees. The return and utility losses we have estimated may be sensitive to our treatment of mutual funds. We have priced mutual funds like any other assets by using the CAPM or the Fama-French model. To check the robustness of our results, we have alternatively estimated the expected return on a fund by: (1) computing its factor loading(s); (2) inferring the corresponding gross expected return from the asset pricing models; (3) computing the net expected return by subtracting a yearly fee of $0.5 \%$ for a bond fund or $1 \%$ for other funds. With this procedure, the median Sharpe ratio loss on the complete portfolio is $45 \%$, which is substantially higher than the $35 \%$ estimate

reported in Table 7 . The corresponding median return and utility losses are respectively $1.57 \%$ and $2.26 \%$ of the complete portfolio on a yearly basis, as compared with the $1.17 \%$ and $1.52 \%$ reported in Table 8 and 9 . The estimated impact of the fee on the return loss is consistent with the following quick calculation. A participant with median return loss holds about $13 \%$ of her complete portfolio in bond funds and $32 \%$ in other funds. Fees therefore increase the return loss by approximately $0.13 \times 0.5 \%+0.32 \times 1.0 \%$, or $0.39 \%$. Mutual fund fees of this magnitude have a meaningful but not overwhelming impact on measured diversification losses. We acknowledge, however, that there is considerable heterogeneity in fees, and view a more careful treatment of mutual funds as deserving of further research.

\section{Who Is Underdiversified?}

We have shown that many Swedish households choose reasonably efficient portfolios, but a few appear to be dramatically underdiversified. We now ask how the characteristics of households predict the characteristics of the portfolios they hold.

\subsection{Demographic Predictors of Household Investment Strategies}

We break the return loss on the complete portfolio into several components. Let $w_{h}$ denote the share of risky assets in the complete portfolio, and let $\beta_{h}$ and $\sigma_{h}$ denote the risk characteristics (beta and standard deviation) of the risky portfolio. Under the CAPM, the household earns an expected excess return $\left(E r_{m}^{e}\right) w_{h} \beta_{h}=w_{h} \sigma_{h} S_{h}$ on its complete portfolio, but could have earned $w_{h} \sigma_{h} S_{B}$ by investing in the benchmark portfolio $B$ while taking the same level of risk. The return loss on the complete portfolio is 
therefore $w_{h} \sigma_{h}\left(S_{B}-S_{h}\right)=\left(E r_{m}^{e}\right) w_{h} \beta_{h}\left(S_{B} / S_{h}-1\right)$. We infer that:

$$
R L_{\text {complete }, h}=\left(E r_{m}^{e}\right) w_{h} \beta_{h} \frac{R S R L_{h}}{1-R S R L_{h}},
$$

where $R S R L_{h}=1-S_{h} / S_{B}$ is the relative Sharpe ratio loss on the household portfolio. This exact decomposition relates the complete return loss to a) the portfolio share of risky assets; b) the risky portfolio's beta; and c) a nonlinear transformation of the relative Sharpe ratio loss.

We report in Table $10 \mathrm{~A}$ the cross-sectional decomposition of $R L_{\text {complete, } h}$ with respect to the hedged world index. We observe that the median loss of $1.2 \%$ corresponds to a risky share of about one half, a beta slightly below unity, and a relative Sharpe ratio loss of about one half. These estimates are roughly consistent with the numbers discussed at the end of Section 4.4.

Cross-sectional variation in return losses is driven primarily by the risky share $w_{h}$ until one reaches the top decile of return losses, when this share flattens out. Within the top decile the risky portfolio's systematic risk exposure $\beta_{h}$ and the level of idiosyncratic risk are important for generating the largest return losses. Table 10B shows similar results with respect to the unhedged world index, except that at the left tail of the distribution some households invest efficiently relative to this index and achieve very small or even negative return losses.

Next we ask how the three determinants of return loss - aggressiveness, systematic risk exposure, and portfolio inefficiency - covary with observable household characteristics. We take the natural log of (5.1) to obtain

$$
\ln R L_{\text {complete }, h}=\ln \left(E r_{m}^{e}\right)+\ln w_{h}+\ln \left|\beta_{h}\right|+\ln \left|\frac{R S R L_{h}}{1-R S R L_{h}}\right|,
$$

and regress each component on demographic variables in Table 11.

The first column of the table shows that the return loss increases with measures of financial sophistication such as wealth, education, the ratio of private pension contributions to income, and liabilities. The remaining columns reveal that these characteristics are typically associated with more efficient investing (lower Sharpe ratio loss), but also considerably higher shares of risky assets. Households with standard predictors of financial sophistication invest more in risky assets and choose more diversified portfolios, but overall they bear higher return losses than unsophisticated households. Conversely, the retired and unemployed dummies are associated with lower investment skills and lower risky shares, which overall result in lower return losses. These regularities are consistent with the view that households are aware of their investment skills and choose their risky shares accordingly.

Consistent with Heaton and Lucas (2000), entrepreneurs tend to invest less in risky financial assets and as a result have lower return losses than the rest of the population. 
The natural interpretation is that entrepreneurs bear idiosyncratic risk in their own private businesses, which discourages them from taking additional risk in public equity.

The results in Table 11 are robust to the choice of the benchmark index. If we measure log return losses relative to the unhedged world index, as in Table 10B, we continue to find that sophisticated households incur higher return losses. ${ }^{20}$

Finally, we acknowledge that the explanatory power of our regressions is quite low. There is considerable heterogeneity in investment strategies which is not captured by the demographic variables in our dataset.

We now look in more detail at what sophisticated households do better to achieve a high Sharpe ratio. In Table 5 we showed that the most important determinants of the idiosyncratic volatility in the risky portfolio appear to be the idiosyncratic volatility of individual assets (treating mutual funds and stocks symmetrically) or the share of individual stocks and the idiosyncratic volatility of those stocks (treating mutual funds as perfectly diversified). In Table 12 we regress these portfolio characteristics onto household attributes. We see that consistent with Table 11, households with higher financial wealth tend to bear less idiosyncratic risk. They are more likely to own individual stocks, but they have a smaller share of their portfolios in individual stocks and invest in less volatile stocks. Unreported regressions show that they also own less concentrated stock portfolios. Large households, and households that contribute to private pension schemes, are also characterized by efficient investment behavior.

In Table 13 we refine our analysis of the complete return loss $R L_{\text {complete } h}$ by considering predictors of extreme portfolio characteristics. We use probit regressions to predict whether a household is in the top $5 \%$ of the population in terms of: (1) return loss; (2) systematic risk exposure of the complete portfolio $\beta_{\text {complete } h}=w_{h} \beta_{h}$; or (3) the relative Sharpe ratio loss of the complete (or risky) portfolio.

Many of the results in Table 13 are consistent with those in Table 11. Once again we observe that measures of financial sophistication tend to predict more efficient but also more aggressive investing. However the balance of these effects, in the return loss regression, is somewhat different now that we are predicting only the probability of an extreme return loss. We find that financial and real-estate wealth are insignificant predictors of extreme return loss, although disposable income and education remain significant. Investors who contribute to private pensions are less likely to have large return losses, while entrepreneurs are more likely to have such losses. This result suggests that while many entrepreneurs invest cautiously to compensate for their private business risk, some entrepreneurs are highly aggressive in their financial portfolios as well as their private business activities.

\footnotetext{
${ }^{20}$ Since some return losses are negative relative to the unhedged world index, we must either truncate the return loss distribution before taking logs, or measure return losses in levels. If we do the latter, we obtain results similar to those reported for extreme return losses in Table 13.
} 
Overall, the population of extreme losers is heterogeneous. It seems to include both clueless households and aggressive financial sophisticates.

\subsection{The Welfare Cost of Nonparticipation}

Economists often argue that nonparticipation in risky asset markets is a serious investment mistake. When calculating the welfare cost of nonparticipation, it is standard to assume that a participating household invests efficiently and therefore earns the equity premium. We have shown, however, that many households are underdiversified. We now take this phenomenon into account and present more realistic estimates of the welfare cost of nonparticipation.

The return loss of a nonparticipant depends on the Sharpe ratio $S_{h}^{*}$ and portfolio volatility $w_{h}^{*} \sigma_{h}^{*}$ that it would select if it participated in financial markets:

$$
R L_{\text {complete }, h}=S_{h}^{*} w_{h}^{*} \sigma_{h}^{*}
$$

We now investigate several scenarios for the total risk $w_{h}^{*} \sigma_{h}^{*}$ and the Sharpe ratio $S_{h}^{*}$.

First, we assume that if the household participated, it would obtain the Sharpe ratio of a diversified index and would choose the average total risk $w_{h}^{*} \sigma_{h}^{*}=9.5 \%$ in the complete portfolios of participants. The nonparticipation return loss $R L_{h}$ is then $4.3 \%$ for a household that would invest in the hedged world index $\left(S_{h}^{*}=45.2 \%\right)$, and $3.3 \%$ for a household that would invest in the unhedged world index $\left(S_{h}^{*}=34.6 \%\right)$. Consistent with earlier research, we find that the cost of nonparticipation is high relative to an efficient risky investment strategy.

It may be more realistic to impute the levels of $S_{h}^{*}$ and $w_{h}^{*} \sigma_{h}^{*}$ from the observable characteristics of nonparticipating households. As a second scenario, we regress the Sharpe ratios and volatilities of participants' complete portfolios on the observable characteristics of Table 3 and apply the results of this regression to nonparticipants. This procedure suggests that the average nonparticipant would select a complete portfolio with Sharpe ratio $S_{h}^{*}=26.9 \%$ and volatility $w_{h}^{*} \sigma_{h}^{*}=8.4 \%$. Both these numbers are slightly lower than the average among participants, because nonparticipating households are demographically similar to participating households that invest cautiously and inefficiently. With these numbers, the estimated return loss on the complete portfolio is only $2.3 \%$.

We can use a similar procedure to compute predicted return losses for specific households. Household $A$ has dummy variables that are all equal to zero. That is, the head of household A is a native Swede who is employed, is not an entrepreneur, does not hold a high-school degree and is not contributing to a private pension plan. The household's non-dummy variables (size, income, log financial and real estate wealth, log liabilities) are set equal to the average among nonparticipants (Table 2). We impute that 
$S_{h}^{*}=27.0 \%$ and $w_{h}^{*} \sigma_{h}^{*}=7.6 \%$, and infer that the nonparticipation return loss is then $2.1 \%$.

Household $B$ has the same characteristics as household $A$, but is an immigrant. The imputed values $S_{h}^{*}=25.9 \%$ and $w_{h}^{*} \sigma_{h}^{*}=8.5 \%$ imply that the nonparticipation return loss is then $2.2 \%$. Similarly, household $C$ has the same chacteristics as household $A$, but is unemployed. The imputed values are $S_{h}^{*}=26.8 \%$ and $w_{h}^{*} \sigma_{h}^{*}=7.6 \%$, and the nonparticipation return loss is then $2.0 \%$. These results suggest that nonparticipation return losses have average values between 2.0 and $2.3 \%$.

Utility-based calculations provide similar estimates. A non-participating agent has imputed risk aversion $\gamma=S_{h}^{*} /\left(w_{h}^{*} \sigma_{h}^{*}\right)$. Given the imputed values $S_{h}^{*}=26.9 \%$ and $w_{h}^{*} \sigma_{h}^{*}=8.4 \%$, we infer that $\gamma=3.2$. By choosing not to participate, the agent thus incurs $U L_{n}=S_{m}^{2} /(2 \gamma)$ or $U L_{n}=3.2 \%$ relative to an agent investing optimally. If the agent participated, he would typically incur $U L_{p}=\left(S_{m}^{2}-S_{h}^{* 2}\right) /(2 \gamma)$, or $U L_{p}=2.1 \%$ relative to an agent investing optimally. The utility loss from non-participation is therefore only $1.1 \%$ when the costs of underdiversification are taken into account.

Overall, we see that the standard analysis considerably overestimates the cost of nonparticipation by ignoring the inefficiency of household portfolios. Households that stay out would likely be down if they entered the market. Once we take account of this effect, nonparticipation appears to be a smaller mistake, and may be easier to rationalize using small frictions such as the participation costs postulated by Haliassos and Bertaut (1995), Vissing-Jorgensen (2003), and Calvet, Gonzalez-Eiras and Sodini (2004).

\section{Has Investment Behavior Changed over Time?}

We have so far investigated the participation and investment behavior of Swedish households at the end of 2002. World stock markets experienced very rapid growth in the late 1990s and then a sharp decline in the early 2000's. The returns on the world index in dollars (including dividends) were $+25 \%$ in $1999,-13 \%$ in $2000,-17 \%$ in 2001 and $-20 \%$ in 2002. The Swedish stock market was even more volatile, with SEK returns of $+91 \%$ in $1999,-12 \%$ in $2000,-18 \%$ in 2001 and $-42 \%$ in 2002 . The volatility and negative returns of the early 2000's may have taught inexperienced investors about financial risk and thus may have modified their participation and diversification behavior during the 1999-2002 period.

To explore this possibility, we recompute all our results for those households in our sample that existed at the end of 1999, the earliest date included in the dataset. To save space we do not report here the corresponding graphs and tables, but summarize our main findings.

Participation is slightly lower in 1999, with $60 \%$ of households holding risky assets 
as compared with $62 \%$ in 2002 . The relation between participation and household demographic and financial characteristics remains broadly unchanged. Probit regression estimates have the same signs in both years, with the exception of the entrepreneur and student dummies. The only notable difference is that the coefficient on wealth is substantially higher in 1999. This finding is consistent with the fact that participants rapidly increased their wealth in the booming stockmarket of the late 1990's.

We next investigate whether the diversification losses of participants differ in 1999. Losses on the risky portfolio are similar in both years, but the stock and complete portfolios generally exhibit higher diversification losses in 1999. We focus for simplicity on the hedged version of the world index, but other benchmarks produce similar differences in investment behavior between 1999 and 2002.

The stock portfolio exhibits higher relative Sharpe ratio losses RSRL in 1999, as illustrated by the median value of 0.54 ( 0.51 in 2002) and the 95th percentile of 0.95 (0.77). Swedish households held poorly diversified stock portfolios at the peak of the stock market.

The risky portfolio, on the other hand, exhibits fairly similar levels of diversification in both years. The RSRL has almost the same median of 0.34 (0.35). The distribution of return losses is also very similar up to the 95th percentile: the median and 95th percentile are respectively $3.0 \%$ and $11.8 \%$ in 1999 . Extreme losses, however, tend to be higher. The 99th percentile of RL equals $29.9 \%$ in 1999 (17.9\% in 2002).

Complete portfolios exhibit higher diversification losses in 1999. The return loss has a median of $1.6 \%$ (1.2\% in 2002), a 95th percentile of $6.7 \%(5.0 \%$ in 2002$)$ and a 99 th percentile of $13.2 \%(9.9 \%)$. The rescaled measures are also higher. For instance, the dollar loss has a median of $\$ 250$ and a 95 th percentile of $\$ 5,560$. These large losses originate in more aggressive positions in 1999. Specifically, the share of risky assets is $52 \%$ in 1999 as compared to $43 \%$ in 2002.

This analysis shows that Swedish households were already taking advantage of diversification through mutual funds in 1999. By 2002, they were also holding more diversified portfolios of individual stocks. The perils of holding stock portfolios concentrated in a few companies or sectors, such as Ericsson or the telecommunications sector, had become apparent during the period. A small group of participants were holding very underdiversified risky portfolios at the millennium. This group had either left the market or made wiser choices by the end of 2002 .

We have also investigated possible changes in the relation between diversification behavior and household characteristics. The risky share regression produces very similar results in 1999. Variables such as education, immigration and household size have almost exactly the same effect on the return loss $R L_{\text {complete }}$ as in 2002. Private pension has an insignificant impact on $R L_{\text {complete }}$. The most notable change is that household wealth tends to increase the risky share and thus the return loss more strongly in 1999. 
However, the impact of household wealth on the diversification loss RSRL is similar across these two years.

Overall, the 1999 data confirm the robustness of the main results of the paper. Richer and more sophisticated households invest more efficiently but also more aggressively, and thus incur higher return losses. This result is actually stronger in 1999 because investors were even more aggressive in that year.

\section{Conclusion}

In this paper, we have taken a first look at the properties of household portfolios using a unique Swedish dataset. We have found that the joint observation of stocks and mutual funds is quantitatively extremely important for the assessment of household diversification. This should not be surprising given that $76 \%$ of Swedish households that own stocks directly also hold mutual funds.

Almost two-thirds (62\%) of households participated in risky asset markets in Sweden at the end of 2002. Participating households allocated on average $40 \%$ of their financial wealth to cash and $60 \%$ to risky assets. Mutual funds represent the largest share of risky assets for most households, except for the very rich whose portfolios are dominated by individual stocks. The dataset permits us to compute the risk characteristics of the portfolio of risky assets. The median volatility is $20.7 \%$, the median systematic exposure $\beta_{h}$ is close to unity, and the average excess return implied by a global version of the CAPM is $6.1 \%$.

We have found that many Swedish households are well diversified. The median return loss implied by the global CAPM is $1.2 \%$ of financial wealth, or $\$ 131$ per year relative to the currency-hedged world index. This loss is modest even though it is very difficult for retail investors to achieve the efficiency of the hedged world index. The median loss relative to the unhedged world index is even smaller, and a majority of Swedish households actually outperform the Sharpe ratio of their own domestic stock index. These encouraging results reflect substantial international diversification, which Swedish households achieve through the equity and balanced funds sold by domestic banks. These numbers ignore fund expenses, assuming that mutual funds, like stocks held directly, offer returns that are described by the global CAPM. Rough calculations assuming equal fees across all mutual funds slightly increase return losses; in future work we hope to be able to measure fund-specific fees and the resulting drag on household investment performance.

While a large fraction of retail investors choose well-diversified portfolios, we also identify the unhappy few that select highly concentrated risky portfolios. For instance, $5 \%$ of the population incur return losses that exceed $5 \%$ of financial wealth or $\$ 2,200$ per year. For $1 \%$ of the population, the losses even reach $10 \%$ of financial wealth, or 
$\$ 7,500$ per year.

We have also considered the $38 \%$ of households that do not participate in risky asset markets. We estimate the return loss from nonparticipation at $4.3 \%$ if we assume that such households would participate by earning the maximum available Sharpe ratio of the hedged global index. But this number overstates the cost of nonparticipation because nonparticipants might not diversify effectively if they did participate. The estimated return loss falls to $2.3 \%$ when we estimate the likely investment performance of nonparticipants.

We have shown that predictors of financial sophistication (such as wealth, income, and education) predict higher levels of participation, higher volatility in risky portfolios, and higher Sharpe ratios. Richer and more sophisticated households invest more efficiently, but they also take more risk so they bear higher costs from portfolio inefficiency.

In this paper we have considered financial portfolios in isolation, ignoring human capital and real estate. We doubt that underdiversified financial portfolios can be rationalized by offsetting risks in human capital or real estate, and previous research by Massa and Simonov (2003) has found no evidence that households pick their directly owned stocks to hedge such risks. However our dataset does contain a great deal of information on both income and real estate holdings, and we plan to exploit this information in future research. 


\section{Appendix}

\subsection{Bank Account Imputation}

The balance of a bank account is frequently unreported when the account yields less than 100 SEK (or $\$ 11$ ) during the year. This problem affects about 2,000, 000 of the 4, 800, 000 households in our 2002 dataset. We have considered two main imputation methods.

The first method takes advantage of the comprehensive nature of the data. We estimate the aggregate value of missing bank balances by taking the difference between: (a) the aggregate household deposits reported to the Swedish Central Bank, and (b) the aggregate bank balances in our dataset. The implied average balance is then assigned to each missing observation.

The second method uses the subsample of individuals (about 250,000) for which we observe the bank account balance even though the earned interest is less than 100 SEK. We regress the balance onto the following observable characteristics: age and squared age of household head, household size, real estate wealth, level and squared level of household disposable income, and financial wealth other than bank accounts. The coefficient of determination is modest $\left(R^{2}=1.2 \%\right)$ but the regression coefficients are highly significant. We use the regression to impute the account balances of individual household members and then aggregate the imputed amounts to infer the household bank account balance. This method is used for computations involving complete portfolios in Figure $5 b$ and in Tables 2, 3, 7-9, 11 and 12. Robustness checks show that the choice of the imputation method has very little impact on the results.

\subsection{Dollar CAPM}

We assume that assets are priced on world markets using the dollar CAPM. Returns in the domestic currency (the Swedish krona) can then be derived in three steps.

Step 1. Dollar CAPM on world markets

Let $r_{f, t}^{\$}$ denote the net simple return on the US T-bill, and $r_{m, t}^{\$}$ the dollar return of the market index. We assume for any asset $j$, the net return $r_{j, t}^{\$}$ in dollars satisfies the dollar CAPM:

$$
r_{j, t}^{\$}-r_{f, t}^{\$}=\left(r_{m, t}^{\$}-r_{f, t}^{\$}\right) \beta_{j}^{\$}+u_{j, t}^{\$},
$$

where the residual $u_{j, t}^{\$}$ has zero mean and is uncorrelated with the market index. This relation is used to price financial assets and portfolios worldwide.

Step 2. Exchange rate

Let $X_{t}$ denote the value of one unit of domestic currency (Swedish krona) in US dollars, and let $x_{t}$ denote the corresponding net return: $x_{t}=X_{t} / X_{t-1}-1$. We consider the 
investment strategy consisting of: $(a)$ converting $\$ 1$ into the domestic currency at date $t-1 ;(b)$ investing the proceeds at the domestic riskless rate $r_{f, t}^{D}$; and $(c)$ converting the investment back into US dollars at date $t$. The gross return on this investment is $\left(1+x_{t}\right)\left(1+r_{f, t}^{D}\right)$. The dollar CAPM implies

$$
\left(1+x_{t}\right)\left(1+r_{f, t}^{D}\right)-\left(1+r_{f, t}^{\$}\right)=\left(r_{m, t}^{\$}-r_{f, t}^{\$}\right) \beta_{x}+v_{t},
$$

where the residual $v_{t}$ has zero correlation with the market excess return.

Step 3. Mean-variance frontier in local currency

From the perspective of a domestic (Swedish) investor, the excess return of an asset $j$ with respect to the domestic interest rate is given by:

$$
r_{j, t}^{e, D}=\frac{1+r_{j, t}^{\$}}{1+x_{t}}-\left(1+r_{f, t}^{D}\right) .
$$

We infer from the dollar CAPM (8.1) and (8.2) that the domestic excess return satisfies

$$
r_{j, t}^{e, D}=\frac{\left(r_{m, t}^{\$}-r_{f, t}^{\$}\right) \beta_{j}+u_{j, t}}{1+x_{t}}
$$

where $\beta_{j}=\beta_{j}^{\$}-\beta_{x}$ and $u_{j, t}=u_{j, t}^{\$}-v_{t}$. When the currency return $x_{t}$ exhibits modest variations around its mean $\bar{x}$, the domestic excess return is reasonably approximated by $\left[\left(r_{m, t}^{\$}-r_{f, t}^{\$}\right) \beta_{j}+u_{j, t}\right] /(1+\bar{x})$. We then infer the domestic version of the dollar CAPM:

$$
r_{j, t}^{e, D}=\left(r_{m, t}^{\$}-r_{f, t}^{\$}\right) \beta_{j}^{D}+u_{j, t}^{D},
$$

where $\beta_{j}^{D}$ and $u_{j, t}^{D}$ are rescaled versions of $\beta_{j}$ and $u_{j, t}$. It is easy to check that under covered interest parity, $r_{m, t}^{\$}-r_{f, t}^{\$}$ is the excess return on a fully hedged portfolio of the world index. ${ }^{21}$ From the perspective of a domestic investor, the global pricing model thus induces a domestic version of the CAPM (8.3) in which the hedged world index plays the role of the efficient benchmark.

The dollar CAPM is implemented as follows:

1. We estimate the sample mean $\overline{r_{m}^{\$}-r_{f}^{\$}}$ and sample variance $\left(\sigma_{m}^{\$}\right)^{2}$ of the world index excess return series in dollars.

\footnotetext{
${ }^{21}$ If we buy a unit of the index and engage in a forward sale of the dollar, we obtain the gross return $\left(1+r_{m, t}^{\$}\right) F_{t-1} / X_{t-1}$. The covered interest parity implies $F_{t-1} / X_{t-1}=\left(1+r_{f, t}^{D}\right) /\left(1+r_{f, t}^{\$}\right)$. The return on the investment is therefore approximately $r_{m, t}^{\$}+r_{f, t}^{D}-r_{f, t}^{\$}$, which corresponds to an excess return equal to $r_{m, t}^{\$}-r_{f, t}^{\$}$.
} 
2. For each asset $j \in\{1, . ., N\}$, we estimate the domestic beta $\beta_{j}^{D}$ by regressing the asset's domestic excess return $r_{j, t}^{e D}$ onto the hedged world index $r_{m, t}^{\$}-r_{f, t}^{\$}$. We then compute the $N \times N$ variance-covariance matrix $\mathbf{R}$ of the regression residuals.

3. We finally infer the mean $\mu_{j}=\overline{r_{m}^{\$}-r_{f}^{\$}} \beta_{j}^{D}$ and variance-covariance matrix $\boldsymbol{\Sigma}^{D}=$ $\left(\sigma_{m}^{\$}\right)^{2} \boldsymbol{\beta}^{D} \boldsymbol{\beta}^{D \prime}+\mathbf{R}$ of domestic excess returns.

The market premium is the sample average over the 1983-2004 period (longest period available). The beta coefficient of each asset/mutual fund is computed using 1994-2004 monthly data (or the available subset for shorter-lived assets).

\subsection{Fama and French Factors}

We assume that asset returns on world markets satisfy the three-factor model:

$$
r_{j, t}^{\$}-r_{f, t}^{\$}=\beta_{j}^{\$} r_{m, t}^{e}+\gamma_{j}^{\$} S M B_{t}+\delta_{j}^{\$} H M L_{t}+u_{j, t}^{\$} \quad(1 \leq j \leq N),
$$

where $r_{m, t}^{e}$ is the excess return of the dollar world index (relative to the US T-bill), and $S M B_{t}$ and $H M L_{t}$ are the US size and value factors. As in Section 8.2, the global Fama French model implies that domestic excess returns (in Swedish kronas relative to the Swedish T-bill) satisfy the three factor model:

$$
r_{j, t}^{e, D}=\beta_{j} r_{m, t}^{e}+\gamma_{j} S M B_{t}+\delta_{j} H M L_{t}+u_{j, t} .
$$

We implement the following estimation procedure:

- Let $\mathbf{f}_{t}=\left(r_{m, t}^{e}, S M B_{t}, H M L_{t}\right)^{\prime}$ denote the column vector of the three factors in date $t$. We compute the sample mean $\overline{\mathbf{f}}=\sum_{t=1}^{T} \mathbf{f}_{t} / T$ and variance-covariance matrix $\boldsymbol{\Sigma}_{F}=\sum_{t=1}^{T}\left(\mathbf{f}_{t}-\overline{\mathbf{f}}\right)\left(\mathbf{f}_{t}-\overline{\mathbf{f}}\right)^{\prime} / T$.

- For each asset $j$, we estimate the loadings $\mathbf{b}_{j}=\left(\beta_{j}, \gamma_{j}, \delta_{j}\right)^{\prime}$ by regressing the domestic excess returns onto the factors:

$$
\mathbf{b}_{j}=\left(\mathbf{F}^{\prime} \mathbf{F}\right)^{-1} \mathbf{F}^{\prime} \mathbf{r}_{\mathbf{j}}^{e}
$$

where $\mathbf{r}_{\mathbf{j}}^{e}=\left(r_{j, 1}^{e} ; \ldots ; r_{j, T}^{e}\right)^{\prime}$ and $\mathbf{F}=\left(\mathbf{f}_{1}, \ldots, \mathbf{f}_{T}\right)^{\prime}$. We then compute the sample variance $\sigma_{u, j}^{2}=\sum_{t=1}^{T}\left(r_{j, t}^{e}-\mathbf{b}_{j}^{\prime} \mathbf{f}_{t}\right)^{2} / T$.

- We then compute the mean domestic excess return $\mu_{j}=\mathbf{b}_{j}^{\prime} \overline{\mathbf{f}}$ on every asset $j$. The variance-covariance matrix of the assets is estimated by

$$
\boldsymbol{\Sigma}=\mathbf{B} \boldsymbol{\Sigma}_{\mathbf{F}} \mathbf{B}^{\prime}+\mathbf{D},
$$

where $\mathbf{B}$ is the matrix of factor loadings $\left(\mathbf{b}_{1}, \ldots, \mathbf{b}_{N}\right)^{\prime}$, and $\mathbf{D}$ is the diagonal matrix with diagonal elements $\sigma_{u, j}^{2}$. 


\subsection{Utility Loss}

Consider a household with an infinite horizon, CRRA utility of consumption with discount factor $\delta$ and risk aversion $\gamma$, and able to invest in two assets: a safe asset with log return $r_{f}$, and a risky asset with $\log$ return $r_{t+1}$ distributed i.i.d. normal, with mean $\mu$ and variance $\sigma^{2}$. We use uppercase letters for levels, and lowercase letters for logs.

The household's problem is

$$
\max E_{t} \sum_{i=0}^{\infty} \delta^{i} \frac{C_{t+i}^{1-\gamma}}{1-\gamma}
$$

subject to

$$
\begin{gathered}
W_{t+1}=\left(W_{t}-C_{t}\right)\left(1+R_{p, t+1}\right) \\
R_{p, t+1}=R_{f}+w\left(R_{t+1}-R_{f}\right) .
\end{gathered}
$$

The usual first-order conditions apply:

$$
\gamma E_{t} \Delta c_{t+1}=\ln (\delta)+r_{f}+\gamma^{2} \sigma_{c}^{2} / 2
$$

where $\sigma_{c}^{2}$ is the variance of consumption, and

$$
\mu-r_{f}+\sigma^{2} / 2=\gamma \sigma_{r c}
$$

where $\sigma_{r c}$ is the covariance of the risky asset return with consumption.

We use the continuous-time approximation to the log portfolio return, as in Campbell and Viceira (2002). That is, we assume

$$
r_{p, t+1}=r_{f}+w\left(r_{t+1}-r_{f}+\sigma^{2} / 2\right)-w^{2} \sigma^{2} / 2 .
$$

We can show that the optimal consumption-wealth ratio $C_{t} / W_{t}$ is a constant in this example. It is convenient to use the notation $x=\ln \left(1-C_{t} / W_{t}\right)$, and use the budget constraint to show that

$$
\Delta c_{t+1}=\Delta w_{t+1}=x+r_{p, t+1} .
$$

The random component of the portfolio return is just $w$ times the risky asset return, so the covariance of the risky asset return with consumption is given by

$$
\sigma_{r c}=w \sigma^{2}
$$

and the optimal portfolio share is the familiar

$$
w=\frac{\mu-r_{f}+\sigma^{2} / 2}{\gamma \sigma^{2}}=\frac{S}{\gamma \sigma},
$$

where $S$ is the Sharpe ratio of the risky asset. 
We can now substitute out the moments of consumption from the consumption growth Euler equation:

$$
\gamma\left(x+E_{t} r_{p, t+1}\right)=\ln (\delta)+r_{f}+\gamma^{2} w^{2} \sigma^{2} / 2
$$

Solving for $x$, we have

$$
x=\frac{\ln (\delta)}{\gamma}-\left(1-\frac{1}{\gamma}\right)\left(r_{f}+\frac{1}{2} \frac{S^{2}}{\gamma}\right) .
$$

The value function per unit wealth can be written as $V_{t}=(1-\delta)^{\frac{-1}{\gamma-1}}\left(C_{t} / W_{t}\right)^{\frac{\gamma}{\gamma-1}}$, or in $\operatorname{logs}$,

$$
v_{t}=\frac{\gamma \ln \left(1-e^{x}\right)-\ln (1-\delta)}{\gamma-1} .
$$

Financial opportunities thus affect the value function through $x$.

This gives us all the ingredients we need to analyze the welfare effect of a change in the Sharpe ratio from an inefficient portfolio $S_{h}$ to an efficient one $S_{B}$. The effect of an increased Sharpe ratio is equivalent to an increase in the riskless interest rate of

$$
\frac{S_{B}^{2}-S_{h}^{2}}{2 \gamma}
$$

We note that this measure of inefficiency increases with the inefficiency measure $S_{B}^{2}-S_{h}^{2}$ and decreases with risk aversion $\gamma$. 


\section{References}

[1] Agnew, J., P. Balduzzi and A. Sunden, 2003, Portfolio choice and trading in a large 401(k) plan, American Economic Review 93(1), 193-215.

[2] Ameriks, John, and Stephen Zeldes, 2004, How do household portfolio shares vary with age?, working paper, Columbia University.

[3] Banks, James, Richard Blundell, and James P. Smith, 2005, Wealth portfolios in the United Kingdom and the United States, in David A. Wise ed. Perspectives on the Economics of Aging (University of Chicago Press, Chicago, IL).

[4] Barber, Brad M., and Terrance Odean, 2001, Boys will be boys: gender, overconfidence, and common stock investment, Quarterly Journal of Economics 116, 261-292.

[5] Barberis, Nicholas, and Richard Thaler, 2003, A survey of behavioral finance, in George Constantinides, Milton Harris and René Stulz eds., Handbook of the Economics of Finance, Elsevier.

[6] Benartzi, Shlomo, and Richard Thaler, 2001, Naive diversification strategies in defined contribution saving plans, American Economic Review 91, 79-98.

[7] Bergstresser, Daniel, and James Poterba, 2004, Asset allocation and asset location: Household evidence from the Survey of Consumer Finances, Journal of Public Economics 88, 1893-1915.

[8] Bertaut, Carol, and Martha Starr-McCluer, 2002, Household portfolios in the United States, in Luigi Guiso, Michael Haliassos and Tullio Jappelli eds. Household Portfolios, MIT Press, Cambridge, MA.

[9] Black, Fischer (1972), Capital Market Equilibrium with Restricted Borrowing, Journal of Business 45, 444-454.

[10] Blume, Marshall, and Irwin Friend, 1975, The asset structure of individual portfolios and some implications for utility functions, Journal of Finance 30, 585-603.

[11] Blume, Marshall, and Irwin Friend, 1978, The Changing Role of the Individual Investor, John Wiley, New York, NY.

[12] Bodie, Zvi, and Dwight Crane, 1997, Personal investing: Advice, theory and evidence, Financial Analysts Journal 53 (6), 13-23. 
[13] Calvet, Laurent E., Martín Gonzalez-Eiras and Paolo Sodini, 2004, Financial innovation, market participation and asset prices, Journal of Financial and Quantitative Analysis 39, 431-459.

[14] Campbell, John Y., Joao Cocco, Francisco Gomes and Pascal Maenhout, 2001, Investing retirement wealth: A life-cycle model, in John Y. Campbell and Martin Feldstein eds., Risk Aspects of Investment-Based Social Security Reform, University of Chicago Press.

[15] Campbell, John Y., and Luis M. Viceira, 2002, Strategic Asset Allocation: Portfolio Choice for Long-Term Investors, Oxford University Press.

[16] Carroll, Christopher D., 2002, Portfolios of the rich, in Luigi Guiso, Michael Haliassos and Tullio Jappelli eds. Household Portfolios, MIT Press, Cambridge, MA.

[17] Choi, James J., David Laibson, Brigitte Madrian, and Andrew Metrick, 2002, Defined contribution pensions: Plan rules, participant decisions, and the path of least resistance, in James Poterba ed. Tax Policy and the Economy 16, 67-113.

[18] Choi, James J., David Laibson, Brigitte Madrian, and Andrew Metrick, 2004, For better or for worse: Default effects and 401(k) savings behavior, in David Wise ed. Perspectives on the Economics of Aging, University of Chicago Press.

[19] Fama, Eugene, and Kenneth French, 1993, Common risk factors in the returns on stocks and bonds, Journal of Financial Economics 33, 3-56.

[20] Flavin, Marjorie, and Takashi Yamashita, 2002, Owner-occupied housing and the composition of the household portfolio, American Economic Review 92 (1), 345362.

[21] Goetzmann, William N., and Alok Kumar, 2004, Why do individual investors hold under-diversified portfolios?, Yale University and University of Notre Dame Working Paper.

[22] Graham, John R., Campbell R. Harvey, and Hai Huang, 2005, Investor competence, trading frequency, and home bias, NBER working paper 11426.

[23] Guiso, Luigi, Michael Haliassos, and Tullio Japelli, 2002, Household Portfolios, MIT Press.

[24] Haliassos, Michael, and Carol Bertaut, 1995, Why do so few hold stocks?, Economic Journal, 105, 1110-1129.

[25] Heaton, John, and Deborah Lucas, 2000, Portfolio choice and asset prices: The importance of entrepreneurial risk, Journal of Finance 55, 1163-1198. 
[26] Huberman, Gur, 2001, Familiarity breeds investment, Review of Financial Studies $14,659-680$.

[27] Ivković, Zoran, Clemens Sialm, and Scott Weisbenner, 2004, Portfolio concentration and the performance of individual investors, NBER working paper 10675.

[28] Ivković, Zoran, and Scott Weisbenner, 2003, Local does as local is: information content of the geography of individual investors' common stock investments, NBER working paper 9685 .

[29] Juster, Thomas, James Smith, and Frank Stafford, 1999, The measurement and structure of household wealth, Labor Economics 6, 253-275.

[30] Kelly, Morgan, 1995, All their eggs in one basket: Portfolio diversification of US households, Journal of Economic Behavior and Organization 27, 87-96.

[31] King, Mervyn A., and Jonathan I. Leape, 1987, Asset accumulation, information and the life cycle, NBER Working Paper 2392.

[32] King, Mervyn A., and Jonathan I. Leape, 1998, Wealth and portfolio composition: Theory and evidence, Journal of Public Economics 69, 155-193.

[33] Kopczuk, Wojciech, and Emmanuel Saez, 2004, Top wealth shares in the United States, 1916-2000: evidence from estate tax returns, NBER working paper 10399.

[34] Madrian, Brigitte and Dennis Shea, 2001, The power of suggestion: Inertia in 401(k) participation and savings behavior, Quarterly Journal of Economics 66, $1149-1188$.

[35] Massa, Massimo, and Andrei Simonov, 2003, Hedging, familiarity and portfolio choice, CEPR working paper 4789, forthcoming Review of Financial Studies.

[36] Odean, Terrance, 1998, Are investors reluctant to realize their losses?, Journal of Finance 53, 1775-1798.

[37] Odean, Terrance, 1999, Do investors trade too much?, American Economic Review 89, 1279-1298.

[38] Poterba, James, and Andrew Samwick, 1997, Portfolio allocation over the life cycle, NBER Working Paper 6185.

[39] Schlarbaum, Gary G., Ronald C. Lease, and Wilbur G. Lewellen, 1978, The common-stock-portfolio performance record of individual investors: 1964-1970, Journal of Finance 33, 429-441. 
[40] Shiller, Robert, 2000, Human behavior and the efficiency of the financial system, in John B. Taylor and Michael Woodford eds., Handbook of Macroeconomics, NorthHolland.

[41] Sinai, Todd and Nicholas Souleles, 2005, Owner-occupied housing as a hedge against rent risk, Quarterly Journal of Economics 120, 763-789.

[42] Solnik, Bruno, and Dennis McLeavey, 2003, International Investments, Pearson Addison Wesley.

[43] Swedish Tax Agency, Taxes in Sweden 2004. Available from the Agency's website, www.skatteverket.se.

[44] Tracy, Joseph, Henry Schneider, and Sewin Chan, 1999, Are stocks overtaking real estate in household portfolios?, Current Issues in Economics and Finance 5:5, Federal Reserve Bank of New York.

[45] Tracy, Joseph, and Henry Schneider, 2001, Stocks in the Household Portolio: A Look Back at the 1990s, Current Issues in Economics and Finance 7:4, Federal Reserve Bank of New York.

[46] Vissing-Jorgensen, Annette, 2002a, Limited asset market participation and the elasticity of intertemporal substitution, Journal of Political Economy 100, 825853.

[47] Vissing-Jorgensen, Annette, 2002b, Towards an explanation of household portfolio choice heterogeneity: Nonfinancial income and participation cost structures, NBER Working Paper 8884.

[48] Vissing-Jorgensen, Annette, 2003, Perspectives on behavioral finance: does "irrationality" disappear with wealth? Evidence from expectations and actions, in Mark Gertler and Kenneth Rogoff eds. NBER Macroeconomics Annual 2003 (MIT Press, Cambridge, MA).

[49] Wermers, Russ, 2000, Mutual fund performance: An empirical decomposition into stock-picking talent, style, transactions costs, and expenses, Journal of Finance 55, 1655-1695.

[50] Zhu, Ning, 2002, The local bias of individual investors, unpublished paper, Yale University. 
TABLE 1. AGGREGATE WEALTH STATISTICS

31 December 2002

\begin{tabular}{|c|c|c|c|c|c|}
\hline & $\begin{array}{r}\text { SCB Statistics } \\
\text { Billion SEK }\end{array}$ & $\begin{array}{r}\text { Data } \\
\text { Billion SEK }\end{array}$ & $\begin{array}{r}\text { Data } \\
\text { Billion Dollars } \\
\end{array}$ & $\begin{array}{r}\text { Wealth Share } \\
\%\end{array}$ & $\begin{array}{r}\text { Financial Share } \\
\% \\
\end{array}$ \\
\hline \multicolumn{6}{|l|}{ Financial Assets } \\
\hline Bank Accounts & 402 & 410.2 & 46.2 & $9.7 \%$ & $35.1 \%$ \\
\hline Money Market Funds & 47 & 64.0 & 7.2 & $1.5 \%$ & $5.5 \%$ \\
\hline Mutual Funds & 273 & 260.5 & 29.4 & $6.1 \%$ & $22.3 \%$ \\
\hline Domestic Stocks & 260 & 244.2 & 27.5 & $5.7 \%$ & $20.9 \%$ \\
\hline International Stocks & $\mathrm{N} / \mathrm{A}$ & 20.8 & 2.3 & $0.5 \%$ & $1.8 \%$ \\
\hline Capital Insurance & 107 & 107.7 & 12.1 & $2.5 \%$ & $9.2 \%$ \\
\hline Bonds and Derivatives & 76 & 61.1 & 6.9 & $1.4 \%$ & $5.2 \%$ \\
\hline Total Financial Assets & 1,165 & $1,168.5$ & 131.7 & $27.5 \%$ & $100.0 \%$ \\
\hline \multicolumn{6}{|l|}{ Real Estate } \\
\hline$\overline{\text { Residential }}$ & 2,523 & $2,704.8$ & 304.8 & $63.7 \%$ & \\
\hline Non-Residential & 533 & 374.5 & 42.2 & $8.8 \%$ & \\
\hline Total Real Estate & 3,056 & $3,079.3$ & 347.0 & $72.5 \%$ & \\
\hline Total Gross Wealth & 4,221 & $4,247.8$ & 478.7 & $100.0 \%$ & \\
\hline \multicolumn{6}{|l|}{ Debt } \\
\hline Student Loans & 146 & 148.4 & 16.7 & & \\
\hline Other Debt & 1,177 & $1,162.9$ & 131.1 & & \\
\hline Total Debt & 1,323 & $1,311.2$ & 147.8 & & \\
\hline Total Net Wealth & 2,898 & $2,936.6$ & 331.0 & & \\
\hline Number of households & $4,869,448$ & $4,869,448$ & $4,869,448$ & & \\
\hline Gross Wealth per Household & SEK 866,833 & SEK 872,342 & $\$ 98,313$ & & \\
\hline Net Wealth per Household & SEK 595,139 & SEK 603,070 & $\$ 67,966$ & & \\
\hline
\end{tabular}


TABLE 2. SUMMARY STATISTICS

\begin{tabular}{|c|c|c|c|c|c|c|c|c|c|}
\hline & \multicolumn{3}{|c|}{ ALL HOUSEHOLDS } & \multicolumn{3}{|c|}{ PARTICIPANTS } & \multicolumn{3}{|c|}{ NONPARTICIPANTS } \\
\hline & Mean & Median & Std Dev & Mean & Median & Std Dev & Mean & Median & Std Dev \\
\hline Disposable Income (\$ per year) & 26,527 & 21,280 & 29,046 & 31,329 & 26,546 & 34,724 & 18,266 & 15,390 & 10,622 \\
\hline Financial Wealth (\$) & 29,180 & 7,191 & 197,304 & 41,586 & 14,563 & 246,730 & 7,834 & 1,262 & 21,190 \\
\hline Complete Portfolio (\$) & - & - & - & 35,553 & 12,467 & 232,120 & - & - & - \\
\hline Risky Portfolio (\$) & - & - & - & 19,515 & 4,372 & 178,641 & - & - & - \\
\hline Stock Portfolio (\$) & - & - & - & 9,261 & 229 & 157,324 & - & - & - \\
\hline Real-Estate Wealth (\$) & 77,394 & 28,879 & 212,155 & 104,960 & 61,133 & 256,660 & 29,967 & 0 & 74,537 \\
\hline Total Liabilities (\$) & 33,050 & 10,011 & 124,799 & 41,434 & 17,113 & 100,748 & 18,626 & 3,524 & 156,780 \\
\hline Log of Financial Wealth & 11.00 & 11.06 & 1.82 & 11.73 & 11.77 & 1.49 & 9.74 & 9.32 & 1.65 \\
\hline Log of Real-Estate Wealth & 8.01 & 12.45 & 6.64 & 9.82 & 13.20 & 6.13 & 4.90 & 0.00 & 6.31 \\
\hline Age & 51.71 & 50.00 & 18.22 & 50.94 & 50.00 & 17.07 & 53.03 & 51.00 & 19.98 \\
\hline High-School Dummy & 0.66 & 1.00 & 0.48 & 0.72 & 1.00 & 0.45 & 0.55 & 1.00 & 0.50 \\
\hline Post High-School Dummy & 0.26 & 0.00 & 0.44 & 0.32 & 0.00 & 0.46 & 0.16 & 0.00 & 0.37 \\
\hline Missing Education & 0.15 & 0.00 & 0.36 & 0.12 & 0.00 & 0.32 & 0.21 & 0.00 & 0.41 \\
\hline Immigration Dummy & 0.15 & 0.00 & 0.35 & 0.11 & 0.00 & 0.31 & 0.21 & 0.00 & 0.41 \\
\hline Household Size & 1.95 & 1.00 & 1.25 & 2.19 & 2.00 & 1.29 & 1.56 & 1.00 & 1.06 \\
\hline Retired Dummy & 0.25 & 0.00 & 0.43 & 0.22 & 0.00 & 0.42 & 0.30 & 0.00 & 0.46 \\
\hline Unemployment Dummy & 0.08 & 0.00 & 0.28 & 0.07 & 0.00 & 0.25 & 0.11 & 0.00 & 0.31 \\
\hline Entrepreneur Dummy & 0.03 & 0.00 & 0.18 & 0.04 & 0.00 & 0.19 & 0.02 & 0.00 & 0.15 \\
\hline Student Dummy & 0.04 & 0.00 & 0.20 & 0.04 & 0.00 & 0.19 & 0.05 & 0.00 & 0.22 \\
\hline Private Pension Premia/Income(\%) & 1.27 & 0.00 & 5.95 & 1.71 & 0.23 & 7.25 & 0.52 & 0.00 & 2.28 \\
\hline Log of Total Liabilities & 8.40 & 11.39 & 5.67 & 9.01 & 11.93 & 5.60 & 7.35 & 10.35 & 5.62 \\
\hline
\end{tabular}

This table reports summary statistics of the main financial and demographic characteristics of Swedish households at the end of 2002 . All logarithms are in the natural base The computations are based on the random sample of 100,000 households considered throughout the empirical analysis. 
TABLE 3. PARTICIPATION AND RISKY ASSET SHARE

\begin{tabular}{|l|rrr|rrr|}
\hline & \multicolumn{3}{|c|}{ PARTICIPATION } & \multicolumn{3}{c|}{ RISKY SHARE OF PARTICIPANTS } \\
& \multicolumn{3}{|c|}{ Probit Regression } & \multicolumn{3}{c|}{ OLS Regression } \\
\cline { 2 - 7 } & Estimate & Std Error & Change & Estimate & Std Error & Change \\
\hline Intercept & -4.852 & 0.049 & - & -0.037 & 0.013 & - \\
Disposable Income & 0.106 & 0.007 & $8.8 \%$ & -0.001 & 0.000 & $-0.5 \%$ \\
Log of Financial Wealth & 0.491 & 0.004 & $22.9 \%$ & 0.045 & 0.001 & $6.7 \%$ \\
Log of Real-Estate Wealth & 0.021 & 0.001 & $4.6 \%$ & 0.000 & 0.000 & $0.3 \%$ \\
Age & -0.014 & 0.001 & $-9.8 \%$ & 0.000 & 0.000 & $-0.2 \%$ \\
High-School Dummy & 0.195 & 0.015 & $7.1 \%$ & 0.021 & 0.004 & $2.1 \%$ \\
Post High-School Dummy & 0.130 & 0.014 & $4.3 \%$ & 0.033 & 0.003 & $3.3 \%$ \\
Missing Education & -0.066 & 0.022 & $-2.3 \%$ & 0.023 & 0.006 & $2.3 \%$ \\
Immigration Dummy & -0.384 & 0.015 & $-14.4 \%$ & -0.023 & 0.004 & $-2.3 \%$ \\
Household Size & -0.009 & 0.006 & $-0.4 \%$ & -0.033 & 0.001 & $-4.2 \%$ \\
Retired Dummy & 0.137 & 0.023 & $4.6 \%$ & -0.001 & 0.005 & $-0.1 \%$ \\
Unemployment Dummy & -0.065 & 0.018 & $-2.3 \%$ & -0.019 & 0.005 & $-1.9 \%$ \\
Entrepreneur Dummy & -0.030 & 0.032 & $-1.0 \%$ & -0.060 & 0.007 & $-6.0 \%$ \\
Student Dummy & 0.028 & 0.026 & $1.0 \%$ & 0.032 & 0.007 & $3.2 \%$ \\
Private Pension Premia/Income & 3.053 & 0.218 & $6.1 \%$ & 0.060 & 0.017 & $0.4 \%$ \\
Log of Total Liabilities & 0.017 & 0.001 & $3.3 \%$ & 0.001 & 0.000 & $0.5 \%$ \\
& & & & & & \\
\hline Adjusted R & & & & & & \\
\hline
\end{tabular}

The first set of three columns reports a probit regression of the participation decision on financial and demographic household characteristics Participation is defined as the ownership of at least one risky asset, and disposable income is rescaled as a multiple of 100,000 SEK. The second set of columns reports an OLS regression of the participants' risky share on the same set of observable characteristics. The risky share is defined as the weight of risky assets in the complete portfolio. For each regression, we report the linear coefficient, standard deviation and marginal effect of each predicting variable. The marginal effect is assessed by computing the impact on the dependent variable of increasing a continuous regressor by one standard deviation, or of setting a dummy variable equal to one. 
TABLE 4. TOTAL VOLATILITY OF RISKY PORTFOLIO

A. Hedged World Index

\begin{tabular}{|c|c|c|c|c|c|c|}
\hline & $\begin{array}{r}\text { Total Risk } \\
\sigma_{\mathrm{h}}(\%)\end{array}$ & $\begin{array}{r}\text { Systematic } \\
\text { Risk } \\
\left|\beta_{\mathrm{h}}\right| \sigma_{\mathrm{B}}(\%) \\
\end{array}$ & $\begin{array}{r}\text { Idiosyncratic } \\
\text { Risk } \\
\sigma_{\mathrm{i}, \mathrm{h}}(\%) \\
\end{array}$ & $\begin{array}{r}\text { Idiosyncratic } \\
\text { Variance Share } \\
\left(\sigma_{\mathrm{i}, \mathrm{h}} / \sigma_{\mathrm{h}}\right)^{2}(\%)\end{array}$ & $\begin{array}{r}\text { Beta } \\
\text { Coefficient } \\
\beta_{h}\end{array}$ & $\begin{array}{r}\text { Excess } \\
\text { Risk } \\
\sigma\left(r_{h}-r_{\text {pop }}\right)(\%) \\
\end{array}$ \\
\hline Std Dev & 14.21 & 4.37 & 14.14 & 13.02 & 0.30 & 14.74 \\
\hline 1st Percentile & 10.98 & 7.76 & 7.77 & 50.06 & 0.53 & 9.19 \\
\hline 5th Percentile & 12.44 & 10.01 & 7.39 & 35.27 & 0.68 & 8.77 \\
\hline 25th Percentile & 17.97 & 11.73 & 13.57 & 57.20 & 0.80 & 5.77 \\
\hline 50th Percentile & 20.73 & 13.57 & 15.57 & 56.72 & 0.92 & 7.34 \\
\hline 75th Percentile & 25.77 & 14.50 & 21.12 & 67.44 & 0.99 & 14.12 \\
\hline 90th Percentile & 36.95 & 16.08 & 33.27 & 81.07 & 1.09 & 30.65 \\
\hline 95th Percentile & 51.48 & 21.57 & 46.56 & 81.68 & 1.47 & 40.86 \\
\hline
\end{tabular}

\section{B. Unhedged World Index}

\begin{tabular}{|c|c|c|c|c|c|c|}
\hline & $\begin{array}{r}\text { Total Risk } \\
\sigma_{\mathrm{h}}(\%)\end{array}$ & $\begin{array}{r}\text { Systematic } \\
\text { Risk } \\
\left|\beta_{h}\right| \sigma_{B}(\%)\end{array}$ & $\begin{array}{r}\text { Idiosyncratic } \\
\text { Risk } \\
\sigma_{\mathrm{i}, \mathrm{h}}(\%)\end{array}$ & $\begin{array}{r}\text { Idiosyncratic } \\
\text { Variance Share } \\
\left(\sigma_{\mathrm{i}, \mathrm{h}} / \sigma_{\mathrm{h}}\right)^{2}(\%)\end{array}$ & $\begin{array}{r}\text { Beta } \\
\text { Coefficient } \\
\beta_{h}\end{array}$ & $\begin{array}{r}\text { Excess } \\
\text { Risk } \\
\sigma\left(r_{h}-r_{\text {pop }}\right)(\%)\end{array}$ \\
\hline Mean & 24.16 & 15.52 & 17.80 & 49.57 & 0.97 & 13.33 \\
\hline Std Dev & 14.21 & 4.69 & 14.36 & 17.10 & 0.29 & 14.74 \\
\hline 1st Percentile & 10.98 & 9.03 & 6.25 & 32.44 & 0.56 & 9.19 \\
\hline 5th Percentile & 12.44 & 11.00 & 5.81 & 21.77 & 0.69 & 8.77 \\
\hline 10th Percentile & 14.60 & 11.64 & 8.66 & 35.86 & 0.73 & 7.85 \\
\hline 25th Percentile & 17.97 & 13.98 & 11.22 & 39.29 & 0.88 & 5.77 \\
\hline 50th Percentile & 20.73 & 15.34 & 13.81 & 44.79 & 0.96 & 7.34 \\
\hline 75th Percentile & 25.77 & 16.47 & 19.59 & 58.27 & 1.03 & 14.12 \\
\hline 90th Percentile & 36.95 & 14.00 & 34.20 & 85.65 & 0.88 & 30.65 \\
\hline 95th Percentile & 51.48 & 24.86 & 44.84 & 75.83 & 1.56 & 40.86 \\
\hline 99th Percentile & 69.56 & 29.82 & 62.43 & 80.47 & 1.87 & 60.02 \\
\hline
\end{tabular}

The first two rows of each panel report the mean and standard deviation of portfolio characteristics in the population of participating households. In the next set of rows, households are sorted by Total Risk and the mean of the 100 households around the corresponding Total Risk percentile is reported. Excess risk is the standard deviation of the difference between the household risky portfolio return and the return of the value-weighted index of household risky portfolios. 
TABLE 5. IDIOSYNCRATIC VOLATILITY OF RISKY PORTFOLIO

\section{A. Equal Treatment of All Assets}

\begin{tabular}{|c|c|c|c|c|c|}
\hline & $\begin{array}{c}\text { Idiosyncratic Risk } \\
\sigma_{\mathrm{i}, \mathrm{h}}(\%) \\
\end{array}$ & $\begin{array}{c}\text { Asset Volatility } \\
\sigma_{\mathrm{a}, \mathrm{h}}(\%) \\
\end{array}$ & $\begin{array}{c}\text { Concentration } \\
\mathrm{C}_{\mathrm{a}, \mathrm{h}}\end{array}$ & $\begin{array}{c}\text { Asset Correlation } \\
\rho_{a, h}\end{array}$ & $\begin{array}{c}\text { Stock Share } \\
D_{h} \\
\end{array}$ \\
\hline Mean & 18.63 & 22.21 & 0.58 & 0.27 & 0.30 \\
\hline Std Dev & 13.78 & 15.00 & 0.31 & 0.16 & 0.38 \\
\hline 5th Percentile & 8.20 & 8.85 & 0.86 & 0.18 & 0.02 \\
\hline 10th Percentile & 9.97 & 12.37 & 0.42 & 0.37 & 0.06 \\
\hline 75th Percentile & 19.78 & 27.81 & 0.36 & 0.21 & 0.58 \\
\hline 90th Percentile & 32.01 & 36.89 & 0.68 & 0.14 & 0.88 \\
\hline 95th Percentile & 44.19 & 49.56 & 0.72 & 0.08 & 0.91 \\
\hline 99th Percentile & 60.05 & 72.59 & 0.70 & 0.12 & 0.83 \\
\hline
\end{tabular}

B. Separate Treatment of Stocks and Mutual Funds

\begin{tabular}{|c|c|c|c|c|c|}
\hline & $\begin{array}{c}\text { Idiosyncratic Risk } \\
\sigma_{\mathrm{i}, \mathrm{h}}(\%) \\
\end{array}$ & $\begin{array}{c}\text { Stock Share } \\
D_{h} \\
\end{array}$ & $\begin{array}{c}\text { Stock Volatility } \\
\sigma_{\mathrm{s}, \mathrm{h}}(\%) \\
\end{array}$ & $\begin{array}{c}\text { Concentration } \\
\mathrm{C}_{\mathrm{s}, \mathrm{h}} \\
\end{array}$ & $\begin{array}{c}\text { Stock Correlation } \\
\rho_{\mathrm{s}, \mathrm{h}}\end{array}$ \\
\hline Mean & 22.34 & 0.51 & 40.06 & 0.69 & 0.06 \\
\hline Std Dev & 16.75 & 0.38 & 20.96 & 0.31 & 0.08 \\
\hline 5th Percentile & 10.28 & 0.14 & 34.66 & 0.74 & 0.03 \\
\hline 10th Percentile & 11.55 & 0.16 & 35.14 & 0.71 & 0.03 \\
\hline 75th Percentile & 25.60 & 0.78 & 40.45 & 0.57 & 0.10 \\
\hline 90th Percentile & 39.81 & 0.89 & 50.26 & 0.72 & 0.08 \\
\hline 95th Percentile & 47.88 & 1.00 & 47.88 & 1.00 & 0.00 \\
\hline 99th Percentile & 84.74 & 0.95 & 94.14 & 0.83 & 0.08 \\
\hline
\end{tabular}

The first two rows of each panel report the mean and standard deviation of portfolio characteristics in the population of participating households. In the next set of rows, households are sorted by Total Risk and the mean of the 1000 households around the corresponding Total Risk percentile is reported. 
TABLE 6. ASSETS MOST WIDELY HELD BY HOUSEHOLDS

\section{A. Stocks}

\begin{tabular}{|c|c|c|c|c|c|c|}
\hline Name & $\begin{array}{r}\text { Direct Holdings } \\
(\text { million \$) }\end{array}$ & $\begin{array}{r}\text { Share of } \\
\text { Household } \\
\text { Stock Wealth }\end{array}$ & $\begin{array}{r}\text { Fraction of } \\
\text { Stockholders }\end{array}$ & $\begin{array}{r}\text { Household } \\
\text { Share of Market } \\
\text { Cap }\end{array}$ & $\begin{array}{r}\text { Relative } \\
\text { Market Cap }\end{array}$ & Sharpe Ratio \\
\hline Ericsson B & 1,977 & $8.6 \%$ & $44.5 \%$ & $18.9 \%$ & $5.2 \%$ & $23.2 \%$ \\
\hline AstraZeneca & 1,467 & $6.4 \%$ & $7.7 \%$ & $10.3 \%$ & $7.1 \%$ & $5.5 \%$ \\
\hline Hennes \& Mauritz B & 1,144 & $5.0 \%$ & $9.7 \%$ & $8.3 \%$ & $6.9 \%$ & $14.0 \%$ \\
\hline SHB A & 1,022 & $4.4 \%$ & $3.9 \%$ & $12.0 \%$ & $4.2 \%$ & $18.9 \%$ \\
\hline Nokia & 976 & $4.2 \%$ & $7.9 \%$ & $33.9 \%$ & $1.4 \%$ & $17.5 \%$ \\
\hline SEB A & 916 & $4.0 \%$ & $15.8 \%$ & $16.6 \%$ & $2.7 \%$ & $15.9 \%$ \\
\hline Pharmacia Corporation SDB & 640 & $2.8 \%$ & $8.1 \%$ & $38.0 \%$ & $0.8 \%$ & $10.1 \%$ \\
\hline Svenska Cellulosa Aktiebolaget & 619 & $2.7 \%$ & $3.2 \%$ & $9.8 \%$ & $3.1 \%$ & $15.3 \%$ \\
\hline FöreningsSparbanken A & 613 & $2.7 \%$ & $19.0 \%$ & $10.0 \%$ & $3.0 \%$ & $27.6 \%$ \\
\hline TeliaSonera & 604 & $2.6 \%$ & $36.8 \%$ & $3.6 \%$ & $8.4 \%$ & $21.7 \%$ \\
\hline
\end{tabular}

\section{B. Risky Mutual Funds}

\begin{tabular}{|c|c|c|c|c|c|c|}
\hline Name & Bank/ Issuer & $\begin{array}{l}\text { English } \\
\text { Translation }\end{array}$ & $\begin{array}{r}\text { Holdings } \\
(\text { million \$) }\end{array}$ & $\begin{array}{r}\text { Share of Risky } \\
\text { Fund Wealth }\end{array}$ & $\begin{array}{r}\text { Fraction of } \\
\text { Risky Fund } \\
\text { Holders }\end{array}$ & Sharpe Ratio \\
\hline FSB/Robur Kapitalinvest & FSB & Capital Invest & 1,911 & $5.2 \%$ & $22.4 \%$ & $29.2 \%$ \\
\hline Nordea Futura & Nordea & Futura & 1,246 & $3.4 \%$ & $8.5 \%$ & $29.2 \%$ \\
\hline FSB/Robur Allemansfond III (ny) & FSB & Every man & 1,110 & $3.0 \%$ & $9.7 \%$ & $31.7 \%$ \\
\hline FSB/Robur Mixfond & FSB & Mixed & 982 & $2.7 \%$ & $9.6 \%$ & $32.0 \%$ \\
\hline FSB/Robur Allemansfond IV (ny) & FSB & Every man & 904 & $2.5 \%$ & $6.5 \%$ & $30.7 \%$ \\
\hline SHB Sverige/Världen & $\mathrm{SHB}$ & Sweden/ World & 787 & $2.2 \%$ & $4.5 \%$ & $36.4 \%$ \\
\hline Nordea Beta & Nordea & Beta & 786 & $2.2 \%$ & $5.3 \%$ & $27.2 \%$ \\
\hline SEB Sverige I & SEB & Sweden & 684 & $1.9 \%$ & $4.3 \%$ & $29.4 \%$ \\
\hline FSB/Robur Allemansfond II & FSB & Every man & 632 & $1.7 \%$ & $3.3 \%$ & $28.6 \%$ \\
\hline SEB Aktiesparfond & SEB & Equity saving & 627 & $1.7 \%$ & $5.3 \%$ & $30.0 \%$ \\
\hline
\end{tabular}


TABLE 6. ASSETS MOST WIDELY HELD BY HOUSEHOLDS (cont.)

\section{Composition of Risky Mutual Funds}

\begin{tabular}{|c|c|c|c|c|c|c|c|}
\hline Fund Name & English Translation & $\begin{array}{r}\text { Domestic } \\
\text { Stocks (\%) }\end{array}$ & $\begin{array}{r}\text { Domestic } \\
\text { Bonds (\%) }\end{array}$ & $\begin{array}{r}\text { International } \\
\text { Stocks (\%) }\end{array}$ & $\begin{array}{r}\text { International } \\
\text { Bonds (\%) }\end{array}$ & Cash (\%) & Futures (\%) \\
\hline FSB/Robur Kapitalinvest & Capital Invest & 45.0 & 0.0 & 54.1 & 0.0 & 0.9 & 0.0 \\
\hline Nordea Futura & Futura & 22.5 & 27.5 & 16.7 & 33.3 & 0.0 & 0.0 \\
\hline FSB/Robur Allemansfond III (ny) & Every man & 60.0 & 0.0 & 38.6 & 0.0 & 1.4 & 0.0 \\
\hline FSB/Robur Mixfond & Mixed & 22.9 & 22.1 & 29.1 & 17.1 & 8.8 & 0.0 \\
\hline FSB/Robur Allemansfond IV (ny) & Every man & 60.0 & 0.0 & 38.9 & 0.0 & 1.1 & 0.0 \\
\hline SHB Sverige/Världen & Sweden/ World & 72.7 & 0.0 & 25.4 & 0.0 & 1.9 & 0.0 \\
\hline Nordea Beta & Beta & 75.0 & 0.0 & 25.0 & 0.0 & 0.0 & 0.0 \\
\hline SEB Sverige I & Sweden & 93.9 & 0.2 & 0.0 & 0.0 & 5.9 & 0.0 \\
\hline FSB/Robur Allemansfond II & Every man & 60.0 & 0.0 & 38.8 & 0.0 & 1.2 & 0.0 \\
\hline SEB Aktiesparfond & Equity saving & 47.6 & 3.8 & 39.5 & 0.0 & 9.6 & -0.5 \\
\hline
\end{tabular}

Aktiesparfond

columns report: the ten stocks that are most widely held by Swedish households. Stocks are sorted by the aggregate value of direct stockholdings (column 1). The following company's market capitalization that is directly held by households; the company's value-weighted share of the Swedish stockmarket; and the stock Sharpe's ratio estimated with the Dollar CAPM. Panel B similarly lists the risky mutual funds with the highest aggregate value in household portfolios. For each fund, we report (1) the managing firm; (2) the English translation of the fund's name; (3) the value of household investments in the fund; (4) its share of aggregate household investments in risky funds; (5) the fraction of households owning the fund among the population of households investing in risky funds; and (6) the fund's Sharpe ratio. The asset allocation of each fund at the end of 2002 is reported in Table C. 
TABLE 7. RELATIVE SHARPE RATIO LOSS

\begin{tabular}{|c|c|c|c|c|c|c|c|c|}
\hline \multirow{2}{*}{$\begin{array}{l}\text { Benchmark } \\
\text { Specification }\end{array}$} & \multicolumn{2}{|c|}{ World Index in USD } & \multicolumn{2}{|c|}{ World Index in SEK } & \multicolumn{2}{|c|}{ Swedish Index in SEK } & \multicolumn{2}{|c|}{ Maximal Sharpe Ratio } \\
\hline & CAPM & $\mathrm{FF}$ & CAPM & $\mathrm{FF}$ & CAPM & $\mathrm{FF}$ & CAPM & $\mathrm{FF}$ \\
\hline Sharpe Ratio (\%) & 45.23 & 45.23 & 34.56 & 35.97 & 27.44 & 31.00 & 40.56 & 45.45 \\
\hline \multicolumn{9}{|c|}{ Complete Portfolios } \\
\hline Mean & 0.38 & 0.35 & 0.19 & 0.18 & -0.02 & 0.05 & 0.31 & 0.35 \\
\hline Std Dev & 0.15 & 0.15 & 0.19 & 0.19 & 0.24 & 0.22 & 0.16 & 0.15 \\
\hline 25th Percentile & 0.29 & 0.25 & 0.07 & 0.06 & -0.16 & -0.09 & 0.21 & 0.26 \\
\hline 50th Percentile & 0.35 & 0.32 & 0.14 & 0.14 & -0.08 & 0.00 & 0.27 & 0.32 \\
\hline 75th Percentile & 0.42 & 0.40 & 0.24 & 0.25 & 0.04 & 0.13 & 0.35 & 0.41 \\
\hline 90th Percentile & 0.55 & 0.53 & 0.41 & 0.41 & 0.26 & 0.31 & 0.50 & 0.53 \\
\hline 95th Percentile & 0.69 & 0.68 & 0.60 & 0.60 & 0.49 & 0.54 & 0.66 & 0.69 \\
\hline 99th Percentile & 0.89 & 0.89 & 0.85 & 0.86 & 0.82 & 0.84 & 0.88 & 0.89 \\
\hline \multicolumn{9}{|c|}{ Stock Portfolios } \\
\hline Mean & 0.52 & 0.48 & 0.37 & 0.34 & 0.21 & 0.24 & 0.47 & 0.48 \\
\hline Std Dev & 0.13 & 0.16 & 0.17 & 0.20 & 0.21 & 0.24 & 0.15 & 0.16 \\
\hline 25th Percentile & 0.42 & 0.40 & 0.25 & 0.24 & 0.05 & 0.12 & 0.36 & 0.40 \\
\hline 50th Percentile & 0.51 & 0.47 & 0.35 & 0.34 & 0.19 & 0.23 & 0.45 & 0.48 \\
\hline 75th Percentile & 0.58 & 0.54 & 0.45 & 0.42 & 0.31 & 0.33 & 0.53 & 0.54 \\
\hline 90th Percentile & 0.69 & 0.69 & 0.60 & 0.61 & 0.49 & 0.55 & 0.66 & 0.69 \\
\hline 95th Percentile & 0.77 & 0.77 & 0.70 & 0.71 & 0.62 & 0.66 & 0.74 & 0.77 \\
\hline 99th Percentile & 0.93 & 0.93 & 0.91 & 0.91 & 0.89 & 0.90 & 0.93 & 0.93 \\
\hline
\end{tabular}

The table reports the cross sectional distribution of relative Sharpe ratio losses on the complete and stock portfolios. The mean and standard deviation of asset returns are computed using two pricing models: the CAPM and the Fama-French three factor model. The market portfolio is proxied by the dollar-denominated World Index. Each set of two columns reports yearly household losses relative to a specific benchmark under the two models. We consider four benchmarks: (1) the MSCI World Index in US dollars; (2) the World Index in Swedish kronas; (3) the MSCl Swedish Index in Swedish kronas; and (4) the highest Sharpe ratio achieved by a household complete portfolio in the sample. 
TABLE 8. RETURN LOSS

\section{A. Loss as a Fraction of Financial Wealth}

\begin{tabular}{|c|c|c|c|c|c|c|c|c|}
\hline Benchmark & \multicolumn{2}{|c|}{ World Index in USD } & \multicolumn{2}{|c|}{ World Index in SEK } & \multicolumn{2}{|c|}{ Swedish Index in SEK } & \multicolumn{2}{|c|}{ Maximal Sharpe Ratio } \\
\hline Specification & CAPM & $\mathrm{FF}$ & CAPM & $\mathrm{FF}$ & CAPM & $\mathrm{FF}$ & CAPM & $\mathrm{FF}$ \\
\hline Sharpe Ratio (\%) & 45.23 & 45.23 & 34.56 & 35.97 & 27.44 & 31.00 & 40.56 & 45.45 \\
\hline \multicolumn{9}{|c|}{ Complete Portfolio Return Loss (\%) } \\
\hline Mean & 1.68 & 1.54 & 0.66 & 0.66 & -0.01 & 0.20 & 1.23 & 1.56 \\
\hline Std Dev & 2.10 & 2.05 & 1.32 & 1.39 & 0.94 & 1.11 & 1.74 & 2.06 \\
\hline 25th Percentile & 0.54 & 0.48 & 0.09 & 0.07 & -0.36 & -0.17 & 0.36 & 0.49 \\
\hline 50th Percentile & 1.17 & 1.04 & 0.30 & 0.29 & -0.11 & 0.00 & 0.79 & 1.06 \\
\hline 75th Percentile & 2.06 & 1.83 & 0.71 & 0.72 & 0.05 & 0.22 & 1.45 & 1.86 \\
\hline 90th Percentile & 3.40 & 3.12 & 1.58 & 1.57 & 0.61 & 0.89 & 2.58 & 3.16 \\
\hline 95th Percentile & 5.04 & 4.71 & 2.65 & 2.69 & 1.17 & 1.68 & 3.97 & 4.76 \\
\hline 99th Percentile & 9.86 & 9.58 & 5.84 & 6.10 & 3.28 & 4.28 & 8.06 & 9.67 \\
\hline \multicolumn{9}{|c|}{ Risky Portfolio Return Loss (\%) } \\
\hline Mean & 4.14 & 3.83 & 1.75 & 1.78 & 0.16 & 0.67 & 3.09 & 3.88 \\
\hline Std Dev & 4.91 & 4.97 & 3.53 & 3.79 & 2.70 & 3.20 & 4.29 & 5.00 \\
\hline 25th Percentile & 2.01 & 1.81 & 0.40 & 0.34 & -0.82 & -0.49 & 1.31 & 1.84 \\
\hline 50th Percentile & 2.92 & 2.55 & 0.87 & 0.86 & -0.39 & 0.02 & 1.97 & 2.59 \\
\hline 75th Percentile & 4.21 & 3.84 & 1.73 & 1.72 & 0.22 & 0.81 & 3.13 & 3.89 \\
\hline 90th Percentile & 8.51 & 7.75 & 4.61 & 4.50 & 1.93 & 2.87 & 6.82 & 7.83 \\
\hline 95th Percentile & 12.16 & 11.86 & 7.07 & 6.91 & 3.20 & 4.65 & 9.92 & 11.97 \\
\hline 99th Percentile & 17.91 & 17.86 & 11.25 & 12.08 & 7.52 & 8.98 & 14.81 & 18.00 \\
\hline
\end{tabular}

Panel A reports the return loss on the complete and risky portfolios as a fraction of complete portfolio wealth. The computations are based on two asset pricing models: the CAPM and the three-factor Fama-French model; the market portfolio is proxied by the dollar-denominated World Index. Each set of two columns reports the cross-sectional distribution of household losses relative to a benchmark. 
TABLE 8. RETURN LOSS (cont.)

\section{B. Rescaled Measures}

\begin{tabular}{|c|c|c|c|c|c|c|c|c|}
\hline \multirow{2}{*}{$\begin{array}{l}\text { Benchmark } \\
\text { Specification }\end{array}$} & \multicolumn{2}{|c|}{ World Index in USD } & \multicolumn{2}{|c|}{ World Index in SEK } & \multicolumn{2}{|c|}{ Swedish Index in SEK } & \multicolumn{2}{|c|}{ Maximal Sharpe Ratio } \\
\hline & CAPM & $\mathrm{FF}$ & CAPM & $\mathrm{FF}$ & CAPM & FF & CAPM & FF \\
\hline \multicolumn{9}{|c|}{ Return Loss in Dollars } \\
\hline Mean & 740 & 638 & 321 & 278 & 43 & 85 & 557 & 646 \\
\hline Std Dev & 2,243 & 1,954 & 1,127 & 1,342 & 768 & 1,648 & 1,756 & 1,978 \\
\hline 25th Percentile & 36 & 33 & 6 & 5 & -55 & -21 & 24 & 33 \\
\hline 50th Percentile & 131 & 118 & 33 & 30 & -8 & 0 & 91 & 120 \\
\hline 75th Percentile & 433 & 383 & 133 & 121 & 4 & 24 & 302 & 389 \\
\hline 90th Percentile & 1,190 & 1,039 & 426 & 388 & 78 & 138 & 847 & 1,056 \\
\hline 95th Percentile & 2,204 & 1,922 & 851 & 762 & 218 & 324 & 1,609 & 1,952 \\
\hline 99th Percentile & 7,565 & 6,341 & 3,244 & 2,892 & 1,129 & 1,521 & 5,640 & 6,429 \\
\hline \multicolumn{9}{|c|}{ Return Loss as a Fraction of Disposable Income (\%) } \\
\hline Mean & 2.13 & 1.88 & 0.86 & 0.79 & 0.02 & 0.20 & 1.58 & 1.91 \\
\hline Std Dev & 9.64 & 9.07 & 5.34 & 5.48 & 3.19 & 3.95 & 7.70 & 9.16 \\
\hline 25th Percentile & 0.14 & 0.13 & 0.02 & 0.02 & -0.20 & -0.08 & 0.10 & 0.13 \\
\hline 50th Percentile & 0.51 & 0.46 & 0.13 & 0.12 & -0.03 & 0.00 & 0.35 & 0.46 \\
\hline 75th Percentile & 1.64 & 1.45 & 0.52 & 0.48 & 0.02 & 0.10 & 1.16 & 1.47 \\
\hline 90th Percentile & 4.48 & 3.94 & 1.62 & 1.53 & 0.32 & 0.57 & 3.21 & 4.00 \\
\hline 95th Percentile & 7.84 & 6.85 & 3.13 & 2.92 & 0.89 & 1.33 & 5.72 & 6.95 \\
\hline 99th Percentile & 23.99 & 20.82 & 11.40 & 10.18 & 4.48 & 5.60 & 18.48 & 21.14 \\
\hline
\end{tabular}

Panel B reports two rescaled measures of household losses: (1) the dollar loss is obtained by multiplying the return loss on the risky (or complete) portfolio considered in Panel A by the dollar value of the risky (complete) portfolio; (2) the loss as a fraction of disposable income is obtained by dividing the dollar loss by the three-year average of household disposable income. The standard deviation of dollar losses is computed by winsorizing the top $0.1 \%$ of the sample. 
TABLE 9. UTILITY LOSS

\begin{tabular}{|c|c|c|c|c|c|c|c|c|}
\hline \multirow{2}{*}{\begin{tabular}{|l|} 
Benchmark \\
Specification
\end{tabular}} & \multicolumn{2}{|c|}{ World Index in USD } & \multicolumn{2}{|c|}{ World Index in SEK } & \multicolumn{2}{|c|}{ Swedish Index in SEK } & \multicolumn{2}{|c|}{ Max Sharpe Ratio } \\
\hline & CAPM & $\mathrm{FF}$ & CAPM & $\mathrm{FF}$ & CAPM & $\mathrm{FF}$ & CAPM & $\mathrm{FF}$ \\
\hline Sharpe Ratio (\%) & 45.23 & 45.23 & 34.56 & 35.97 & 27.44 & 31.00 & 40.56 & 45.45 \\
\hline \multicolumn{9}{|c|}{ Utility Loss as a Fraction of Wealth (\%) } \\
\hline Mean & 2.62 & 2.36 & 0.98 & 0.99 & 0.14 & 0.38 & 1.85 & 2.39 \\
\hline Std Dev & 4.30 & 4.22 & 2.33 & 2.52 & 1.40 & 1.82 & 3.36 & 4.26 \\
\hline 25th Percentile & 0.70 & 0.61 & 0.10 & 0.08 & -0.33 & -0.17 & 0.43 & 0.62 \\
\hline 50th Percentile & 1.52 & 1.32 & 0.34 & 0.32 & -0.10 & 0.00 & 0.96 & 1.34 \\
\hline 75th Percentile & 2.79 & 2.43 & 0.84 & 0.86 & 0.06 & 0.25 & 1.86 & 2.48 \\
\hline 90th Percentile & 5.27 & 4.70 & 2.26 & 2.24 & 0.81 & 1.21 & 3.85 & 4.77 \\
\hline 95th Percentile & 8.25 & 7.46 & 3.90 & 3.94 & 1.77 & 2.41 & 6.21 & 7.56 \\
\hline 99th Percentile & 18.09 & 17.40 & 9.18 & 9.68 & 4.90 & 6.37 & 13.87 & 17.59 \\
\hline \multicolumn{9}{|c|}{ Utility Loss in Dollars } \\
\hline Mean & 1,204 & 1,006 & 487 & 430 & 116 & 175 & 867 & 1,021 \\
\hline Std Dev & 3,766 & 3,175 & 1,645 & 1,711 & 882 & 1,592 & 2,727 & 3,227 \\
\hline 25th Percentile & 47 & 43 & 7 & 5 & -52 & -20 & 31 & 44 \\
\hline 50th Percentile & 178 & 155 & 38 & 35 & -8 & 0 & 114 & 158 \\
\hline 75th Percentile & 596 & 513 & 162 & 147 & 5 & 28 & 394 & 522 \\
\hline 90th Percentile & 1,664 & 1,428 & 552 & 500 & 102 & 178 & 1,137 & 1,453 \\
\hline 95th Percentile & 3,146 & 2,685 & 1,119 & 1,013 & 300 & 446 & 2,184 & 2,732 \\
\hline 99th Percentile & 11,020 & 9,048 & 4,452 & 4,043 & 1,575 & 2,157 & 7,918 & 9,176 \\
\hline \multicolumn{9}{|c|}{ Utility Loss as a Fraction of Disposable Income (\%) } \\
\hline Mean & 3.36 & 2.86 & 1.28 & 1.17 & 0.21 & 0.42 & 2.38 & 2.91 \\
\hline Std Dev & 20.96 & 18.61 & 11.05 & 10.69 & 6.36 & 7.42 & 16.24 & 18.83 \\
\hline 25th Percentile & 0.19 & 0.17 & 0.03 & 0.02 & -0.19 & -0.07 & 0.12 & 0.17 \\
\hline 50th Percentile & 0.68 & 0.59 & 0.15 & 0.13 & -0.03 & 0.00 & 0.44 & 0.60 \\
\hline 75th Percentile & 2.28 & 1.95 & 0.63 & 0.58 & 0.02 & 0.11 & 1.51 & 1.99 \\
\hline 90th Percentile & 6.44 & 5.52 & 2.10 & 1.99 & 0.41 & 0.73 & 4.39 & 5.62 \\
\hline 95th Percentile & 11.57 & 9.90 & 4.31 & 3.96 & 1.27 & 1.84 & 8.14 & 10.06 \\
\hline 99th Percentile & 39.07 & 32.46 & 16.60 & 15.28 & 6.96 & 8.84 & 28.25 & 32.94 \\
\hline
\end{tabular}

The table reports utility losses as a fraction of complete portfolio wealth, utility losses in dollars, and utility losses as a fraction of disposable income. A three-year average is used for disposable income to smooth out transitory variations. The standard deviation of utility losses (as a fraction of wealth) and dollar losses are computed by winsorizing the top $0.1 \%$ of the sample. 
TABLE 10. CROSS-SECTIONAL DECOMPOSITION OF COMPLETE RETURN LOSS

\section{A. Losses Relative to Hedged World Index}

\begin{tabular}{|c|c|c|c|c|}
\hline & $\begin{array}{c}\text { Return Loss } \\
\text { RL complete,h (\%) }\end{array}$ & $\begin{array}{c}\text { Risky Share } \\
w_{h} \\
\end{array}$ & $\begin{array}{c}\text { Risky Portfolio } \\
\text { Beta } \\
\beta_{h}\end{array}$ & $\begin{array}{c}\text { Diversification } \\
\text { Loss } \\
\text { RSRL }_{h} /\left(1-R S R L_{h}\right)\end{array}$ \\
\hline Mean & 1.68 & 0.45 & 0.90 & 0.78 \\
\hline Std Dev & 2.10 & 0.30 & 0.38 & 10.89 \\
\hline 1st Percentile & 0.01 & 0.01 & 0.88 & 0.72 \\
\hline 5th Percentile & 0.09 & 0.03 & 0.90 & 0.95 \\
\hline 10th Percentile & 0.19 & 0.08 & 0.90 & 0.93 \\
\hline 25th Percentile & 0.54 & 0.25 & 0.84 & 0.69 \\
\hline 50th Percentile & 1.17 & 0.49 & 0.82 & 0.98 \\
\hline 75th Percentile & 2.06 & 0.70 & 0.89 & 0.59 \\
\hline 90th Percentile & 3.40 & 0.71 & 0.97 & 1.02 \\
\hline 95th Percentile & 5.04 & 0.71 & 1.15 & 1.44 \\
\hline 99th Percentile & 9.86 & 0.77 & 1.46 & 1.96 \\
\hline
\end{tabular}

B. Losses Relative to Unhedged World Index

\begin{tabular}{|l|c|ccc|}
\hline & Return Loss & Risky Share & $\begin{array}{c}\text { Risky Portfolio } \\
\text { Beta } \\
\boldsymbol{\beta}_{\mathbf{h}}\end{array}$ & $\begin{array}{c}\text { Diversification } \\
\text { Loss }\end{array}$ \\
\hline Rean & $\mathbf{W}_{\text {complete, } \mathbf{h}} \mathbf{( \% )}$ & 0.90 & 0.36 \\
Std Dev & 0.66 & 0.45 & 0.38 & 8.32 \\
\hline 1st Percentile & 1.32 & 0.30 & 1.15 & -0.06 \\
5th Percentile & -0.24 & 0.60 & 0.99 & -0.03 \\
10th Percentile & -0.04 & 0.33 & 0.86 & 0.57 \\
25th Percentile & 0.00 & 0.08 & 0.87 & 0.14 \\
50th Percentile & 0.09 & 0.20 & 0.84 & 0.36 \\
75th Percentile & 0.30 & 0.43 & 0.87 & 0.48 \\
90th Percentile & 1.58 & 0.64 & 1.17 & 0.57 \\
95th Percentile & 2.65 & 0.54 & 1.13 & 0.57 \\
99th Percentile & 5.84 & 0.66 & 1.32 & 1.10 \\
\hline
\end{tabular}

The table reports the cross-sectional decomposition of return losses on the complete portfolio. The diversification loss is computed by winsorizing the top $0.1 \%$ of the sample. 
TABLE 11. CONTRIBUTORS TO COMPLETE RETURN LOSS

\begin{tabular}{|c|c|c|c|c|c|c|c|c|c|c|c|c|}
\hline & \multicolumn{3}{|c|}{$\begin{array}{l}\text { Return Loss } \\
\text { In(RL } \text { complete, })\end{array}$} & \multicolumn{3}{|c|}{$\begin{array}{l}\text { Risky Share } \\
\quad \ln \left(w_{h}\right)\end{array}$} & \multicolumn{3}{|c|}{$\begin{array}{l}\text { Risky Portfolio Beta } \\
\qquad \ln \left|\beta_{h}\right|\end{array}$} & \multicolumn{3}{|c|}{$\begin{array}{l}\text { Diversification Loss } \\
\text { In| RSRL } h /\left(1-R S R L_{h}\right) \mid\end{array}$} \\
\hline & Estimate & Std Err & Change & Estimate & Std Err & Change & Estimate & Std Err & Change & Estimate & Std Err & Change \\
\hline Intercept & -1.093 & 0.055 & - & -2.752 & 0.053 & - & -0.108 & 0.027 & - & -0.127 & 0.030 & - \\
\hline Disposable Income & 0.007 & 0.002 & $2.1 \%$ & -0.007 & 0.002 & $-2.1 \%$ & 0.009 & 0.001 & $2.7 \%$ & 0.005 & 0.001 & $1.5 \%$ \\
\hline Log of Financial Wealth & 0.090 & 0.004 & $14.1 \%$ & 0.137 & 0.004 & $22.3 \%$ & -0.016 & 0.002 & $-2.2 \%$ & -0.032 & 0.002 & $-4.5 \%$ \\
\hline Log of Real-Estate Wealth & 0.008 & 0.001 & $5.1 \%$ & 0.005 & 0.001 & $3.2 \%$ & 0.003 & 0.001 & $2.1 \%$ & 0.000 & 0.001 & $-0.3 \%$ \\
\hline Age & -0.001 & 0.001 & $-1.9 \%$ & -0.001 & 0.001 & $-1.9 \%$ & -0.002 & 0.000 & $-3.7 \%$ & 0.002 & 0.000 & $3.8 \%$ \\
\hline High-School Dummy & 0.111 & 0.016 & $10.5 \%$ & 0.107 & 0.016 & $10.2 \%$ & 0.057 & 0.008 & $5.6 \%$ & -0.053 & 0.009 & $-5.5 \%$ \\
\hline Post High-School Dummy & 0.173 & 0.013 & $18.9 \%$ & 0.124 & 0.013 & $13.2 \%$ & 0.042 & 0.007 & $4.3 \%$ & 0.006 & 0.007 & $0.6 \%$ \\
\hline Missing Education & 0.112 & 0.024 & $11.9 \%$ & 0.087 & 0.024 & $9.1 \%$ & -0.037 & 0.012 & $-3.7 \%$ & 0.063 & 0.013 & $6.5 \%$ \\
\hline Immigration Dummy & 0.043 & 0.017 & $4.4 \%$ & -0.112 & 0.017 & $-10.6 \%$ & 0.045 & 0.009 & $4.6 \%$ & 0.110 & 0.009 & $11.6 \%$ \\
\hline Household Size & -0.143 & 0.005 & $-16.9 \%$ & -0.086 & 0.005 & $-10.5 \%$ & -0.010 & 0.002 & $-1.3 \%$ & -0.047 & 0.003 & $-5.9 \%$ \\
\hline Retired Dummy & -0.043 & 0.022 & $-4.2 \%$ & -0.023 & 0.021 & $-2.3 \%$ & -0.050 & 0.011 & $-4.9 \%$ & 0.031 & 0.012 & $3.1 \%$ \\
\hline Unemployment Dummy & -0.086 & 0.021 & $-8.2 \%$ & -0.105 & 0.021 & $-9.9 \%$ & -0.001 & 0.011 & $-0.1 \%$ & 0.020 & 0.012 & $2.0 \%$ \\
\hline Entrepreneur Dummy & -0.115 & 0.029 & $-10.8 \%$ & -0.261 & 0.028 & $-22.9 \%$ & 0.097 & 0.014 & $10.2 \%$ & 0.049 & 0.016 & $5.0 \%$ \\
\hline Student Dummy & 0.020 & 0.031 & $2.0 \%$ & 0.069 & 0.030 & $7.1 \%$ & -0.053 & 0.015 & $-5.2 \%$ & 0.004 & 0.017 & $0.4 \%$ \\
\hline Private Pension Premia/Income & 0.248 & 0.074 & $1.8 \%$ & 0.352 & 0.071 & $2.6 \%$ & -0.016 & 0.037 & $-0.1 \%$ & -0.087 & 0.040 & $-0.6 \%$ \\
\hline Log of Total Liabilities & 0.012 & 0.001 & $7.0 \%$ & 0.004 & 0.001 & $2.3 \%$ & 0.010 & 0.001 & $5.6 \%$ & -0.002 & 0.001 & $-0.9 \%$ \\
\hline Adjusted $\mathrm{R}^{2}$ & 0.034 & & & 0.039 & & & 0.050 & & & 0.030 & & \\
\hline
\end{tabular}

This table reports a probit regression of the complete return loss and its three components on observable household characteristics. Losses are computed relative to the hedged world index. Since $\ln \left(R L_{\text {complete, } h}\right)=\ln \left(w_{h}\right)+\ln \left|\beta_{h}\right|+\ln \left|R S R L_{h} /\left(1-R S R L_{h}\right)\right|$, the estimate for the complete loss is the sum of the three other estimates. 
TABLE 12. IDIOSYNCRATIC VOLATILITY AND HOUSEHOLD CHARACTERISTICS

\begin{tabular}{|c|c|c|c|c|c|c|c|c|c|c|}
\hline & \multicolumn{2}{|c|}{\begin{tabular}{|c|} 
Idiosyncratic \\
Volatility of Risky \\
Portfolio \\
$\sigma_{\mathrm{i}, \mathrm{h}}(\%)$
\end{tabular}} & \multicolumn{2}{|c|}{$\begin{array}{c}\text { Probit } \\
\text { Regression of } \\
\text { Direct Stock } \\
\text { Ownership }\end{array}$} & \multicolumn{2}{|c|}{$\begin{array}{c}\text { Idiosyncratic } \\
\text { Volatility of } \\
\text { Individual Assets } \\
\sigma_{\mathrm{a}, \mathrm{h}}(\%)\end{array}$} & \multicolumn{2}{|c|}{$\begin{array}{c}\text { Share of Direct } \\
\text { Stockholdings in } \\
\text { Risky Portfolio } \\
D_{h}\end{array}$} & \multicolumn{2}{|c|}{$\begin{array}{c}\text { Idiosyncratic } \\
\text { Volatility of } \\
\text { Individual Stocks } \\
\sigma_{\mathrm{s}, \mathrm{h}}(\%)\end{array}$} \\
\hline & Estimate & Std Err & Estimate & Std Err & Estimate & Std Err & Estimate & Std Err & Estimate & Std Err \\
\hline Intercept & 26.470 & 0.912 & -3.675 & 0.062 & 14.858 & 0.995 & 1.122 & 0.031 & 61.319 & 1.902 \\
\hline Disposable Income & 0.198 & 0.024 & 0.096 & 0.005 & 0.266 & 0.026 & 0.008 & 0.001 & 0.167 & 0.039 \\
\hline Log of Financial Wealth & -0.881 & 0.061 & 0.295 & 0.005 & 0.304 & 0.067 & -0.057 & 0.002 & -1.470 & 0.123 \\
\hline Log of Real-Estate Wealth & -0.012 & 0.015 & 0.014 & 0.001 & -0.001 & 0.017 & -0.003 & 0.001 & -0.155 & 0.034 \\
\hline Age & -0.008 & 0.008 & 0.003 & 0.001 & -0.021 & 0.008 & 0.001 & 0.000 & -0.206 & 0.016 \\
\hline High-School Dummy & -0.459 & 0.218 & 0.022 & 0.017 & -0.10 & 0.237 & -0.02 & 0.007 & 1.371 & 0.450 \\
\hline Post High-School Dummy & 0.496 & 0.164 & 0.122 & 0.014 & 1.001 & 0.179 & 0.008 & 0.005 & -0.178 & 0.328 \\
\hline Missing Education & 0.612 & 0.494 & -0.133 & 0.027 & 0.702 & 0.538 & 0.019 & 0.015 & 3.422 & 0.947 \\
\hline Immigration Dummy & 3.246 & 0.226 & 0.119 & 0.019 & 3.462 & 0.246 & 0.105 & 0.007 & 3.090 & 0.45 \\
\hline Household Size & -1.154 & 0.060 & -0.134 & 0.006 & -1.567 & 0.066 & -0.046 & 0.002 & -0.479 & 0.124 \\
\hline Retired Dummy & -0.228 & 0.329 & -0.030 & 0.025 & -0.385 & 0.359 & 0.010 & 0.010 & 0.973 & 0.623 \\
\hline Unemployment Dummy & 0.368 & 0.273 & 0.003 & 0.023 & 0.347 & 0.298 & 0.042 & 0.010 & 0.152 & 0.614 \\
\hline Entrepreneur Dummy & 2.649 & 0.379 & 0.366 & 0.033 & 2.992 & 0.413 & 0.097 & 0.011 & 0.253 & 0.694 \\
\hline Student Dummy & -0.741 & 0.371 & -0.017 & 0.033 & -1.134 & 0.404 & 0.001 & 0.014 & -1.360 & 0.877 \\
\hline Private Pension Premia/ Income & -6.378 & 2.021 & 0.000 & 0.072 & -5.085 & 2.204 & -0.421 & 0.060 & 0.471 & 3.704 \\
\hline Log of Total Liabilities & 0.423 & 0.049 & 0.018 & 0.001 & 0.628 & 0.054 & 0.009 & 0.002 & 0.677 & 0.096 \\
\hline Adjusted $\mathrm{R}^{2}$ & 0.025 & & & & 0.024 & & 0.096 & & 0.036 & \\
\hline
\end{tabular}

The first set of column reports the results of an OLS regression of the idiosyncratic volatility of the risky portfolio (relative to the hedged world index) onto demographic and financial household characteristics. The second set of columns reports a probit regression of direct investment in individual stocks. The next three set of columns reports OLS regressions of the following dependent variables: the average idiosyncratic volatility of individual assets (identical treatment in the terminology of Section 4.2); the share of direct stockholdings in the risky portfolio; and the average idiosyncratic volatility of individual stocks. Disposable income is rescaled as a multiple of 100,000 SEK. 
TABLE 13. PREDICTORS OF EXTREME PORTFOLIO CHARACTERISTICS

\begin{tabular}{|c|c|c|c|c|c|c|c|c|c|}
\hline & \multicolumn{3}{|c|}{$\begin{array}{l}\text { Return Loss } \\
\text { RL }_{\text {complete, }}(\%)\end{array}$} & \multicolumn{3}{|c|}{$\begin{array}{c}\text { Beta } \\
\beta_{\text {complete, } h}\end{array}$} & \multicolumn{3}{|c|}{$\begin{array}{c}\text { Diversification Loss } \\
\text { RSRL }_{h} /\left(1-R S R L_{h}\right)\end{array}$} \\
\hline & Estimate & Std Err & Change & Estimate & Std Err & Change & Estimate & Std Err & Change \\
\hline Intercept & -1.331 & 0.092 & - & -2.051 & 0.094 & - & -0.391 & 0.093 & - \\
\hline Disposable Income & 0.014 & 0.002 & $0.4 \%$ & 0.010 & 0.002 & $0.3 \%$ & 0.002 & 0.004 & $0.1 \%$ \\
\hline Log of Financial Wealth & -0.004 & 0.008 & $-0.1 \%$ & 0.059 & 0.008 & $0.8 \%$ & -0.108 & 0.008 & $-1.1 \%$ \\
\hline Log of Real-Estate Wealth & 0.000 & 0.002 & $0.0 \%$ & 0.003 & 0.002 & $0.2 \%$ & -0.004 & 0.002 & $-0.2 \%$ \\
\hline Age & -0.004 & 0.001 & $-0.5 \%$ & -0.006 & 0.001 & $-0.9 \%$ & 0.007 & 0.001 & $1.1 \%$ \\
\hline High-School Dummy & 0.024 & 0.029 & $0.2 \%$ & 0.106 & 0.030 & $0.9 \%$ & -0.164 & 0.027 & $-1.6 \%$ \\
\hline Post High-School Dummy & 0.097 & 0.022 & $0.9 \%$ & 0.078 & 0.022 & $0.8 \%$ & -0.060 & 0.025 & $-0.5 \%$ \\
\hline Missing Education & 0.089 & 0.047 & $0.8 \%$ & 0.058 & 0.050 & $0.5 \%$ & 0.020 & 0.036 & $0.2 \%$ \\
\hline Immigration Dummy & 0.336 & 0.027 & $3.8 \%$ & 0.280 & 0.027 & $3.2 \%$ & 0.180 & 0.028 & $1.8 \%$ \\
\hline Household Size & -0.192 & 0.009 & $-1.7 \%$ & -0.203 & 0.009 & $-1.9 \%$ & -0.072 & 0.010 & $-0.7 \%$ \\
\hline Retired Dummy & -0.085 & 0.040 & $-0.7 \%$ & -0.078 & 0.040 & $-0.6 \%$ & 0.031 & 0.037 & $0.3 \%$ \\
\hline Unemployment Dummy & 0.059 & 0.035 & $0.5 \%$ & 0.051 & 0.035 & $0.5 \%$ & 0.019 & 0.037 & $0.2 \%$ \\
\hline Entrepreneur Dummy & 0.161 & 0.048 & $1.6 \%$ & 0.131 & 0.047 & $1.3 \%$ & 0.032 & 0.051 & $0.3 \%$ \\
\hline Student Dummy & -0.072 & 0.048 & $-0.6 \%$ & -0.133 & 0.049 & $-1.1 \%$ & 0.094 & 0.054 & $0.9 \%$ \\
\hline Private Pension Premia/ Income & -0.638 & 0.303 & $-0.4 \%$ & -0.170 & 0.251 & $-0.1 \%$ & -1.231 & 0.369 & $-0.7 \%$ \\
\hline Log of Total Liabilities & 0.020 & 0.002 & $1.1 \%$ & 0.026 & 0.002 & $1.5 \%$ & -0.012 & 0.002 & $-0.5 \%$ \\
\hline
\end{tabular}

This table reports probit regressions that a household portfolio is in the top $5 \%$ in terms of: (1) return losses (2) beta of complete portfolio; and (3) the diversification loss RSRL $/(1-$ RSRL $L_{h}$ ). Disposable income is rescaled as a multiple of 100,000 SEK. For each probit, we report the regression coefficient, standard deviation and marginal effect of each predicting variable. The marginal effect is assessed by computing the impact on the dependent variable of increasing a continuous regressor by one standard deviation, or of setting a dummy variable equal to one. 
FIGURE 1. WEALTH DISTRIBUTION

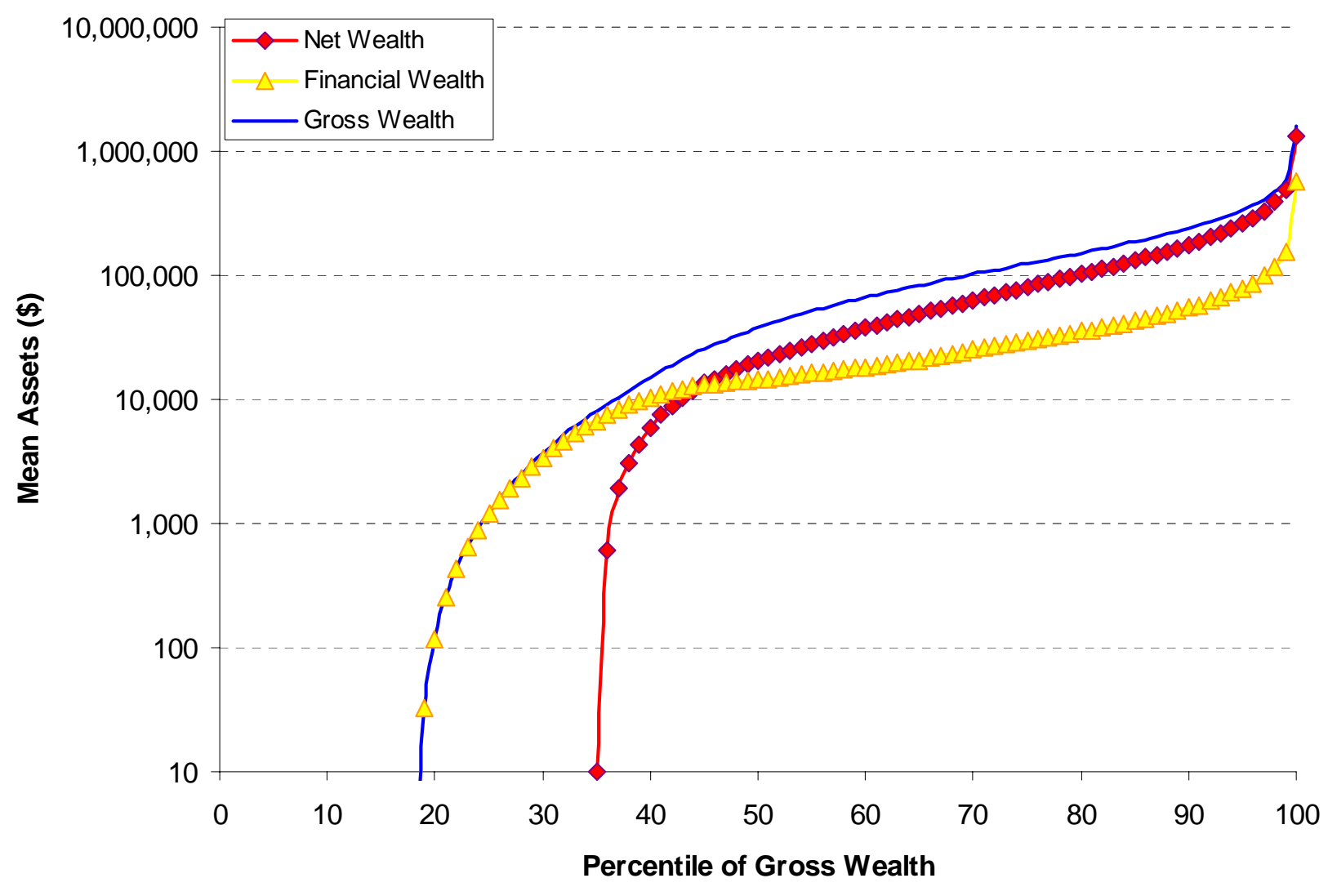


FIGURE 2. COMPOSITION OF FINANCIAL AND REAL ESTATE PORTFOLIO

A. Variation with Gross Wealth

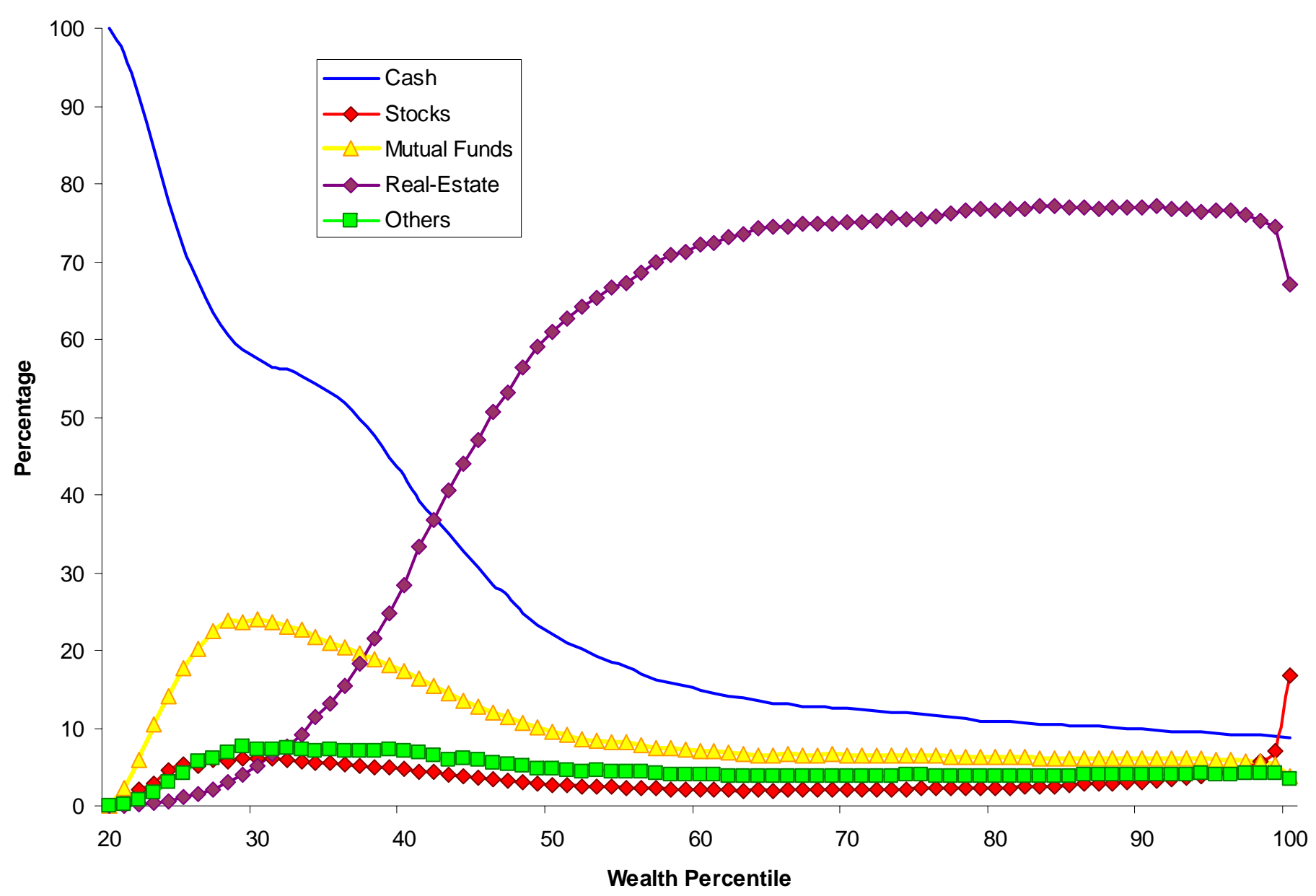




\section{B. Variation with Age of Household Head}

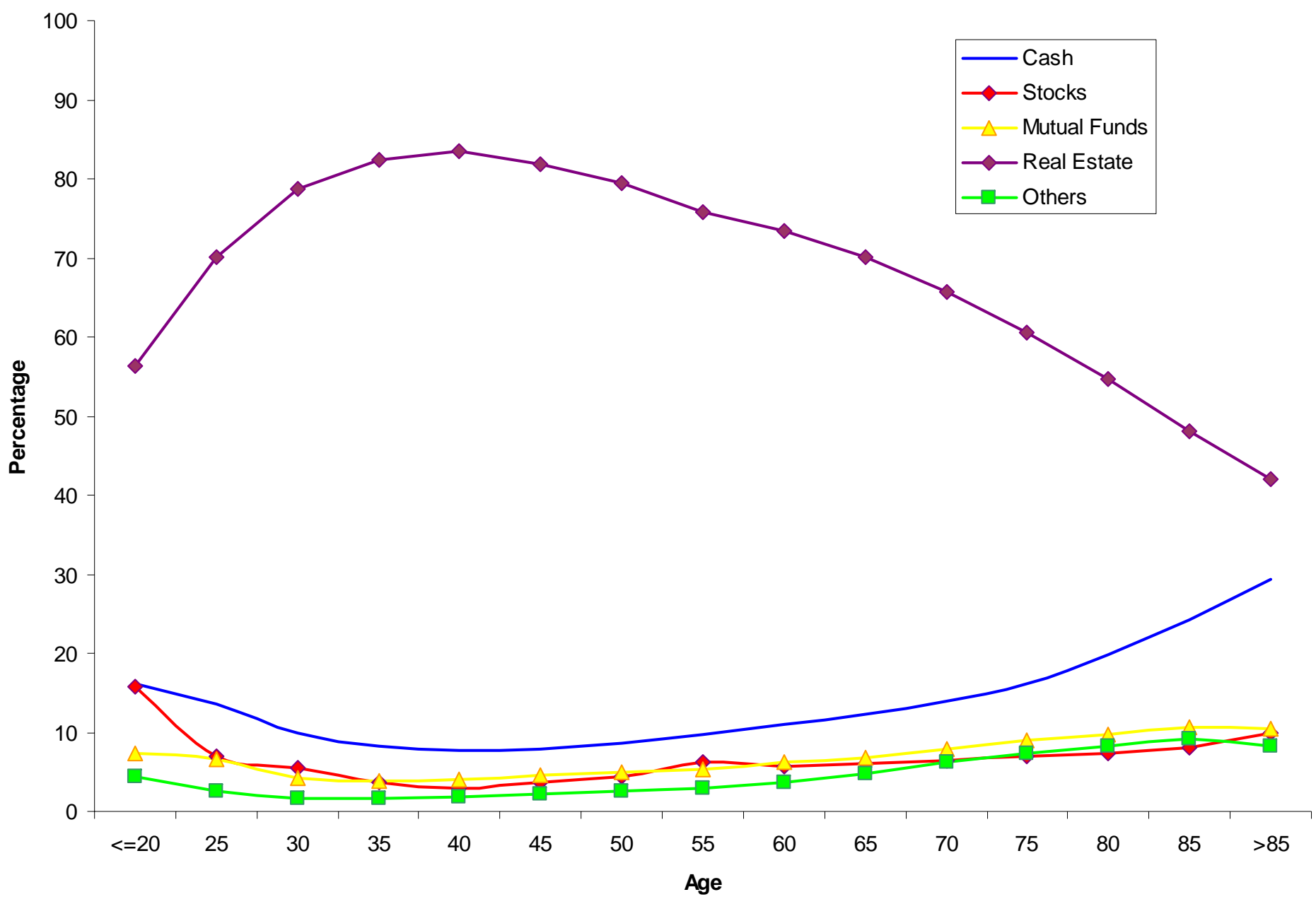


FIGURE 3. COMPOSITION OF FINANCIAL PORTFOLIO

A. Variation with Gross Wealth

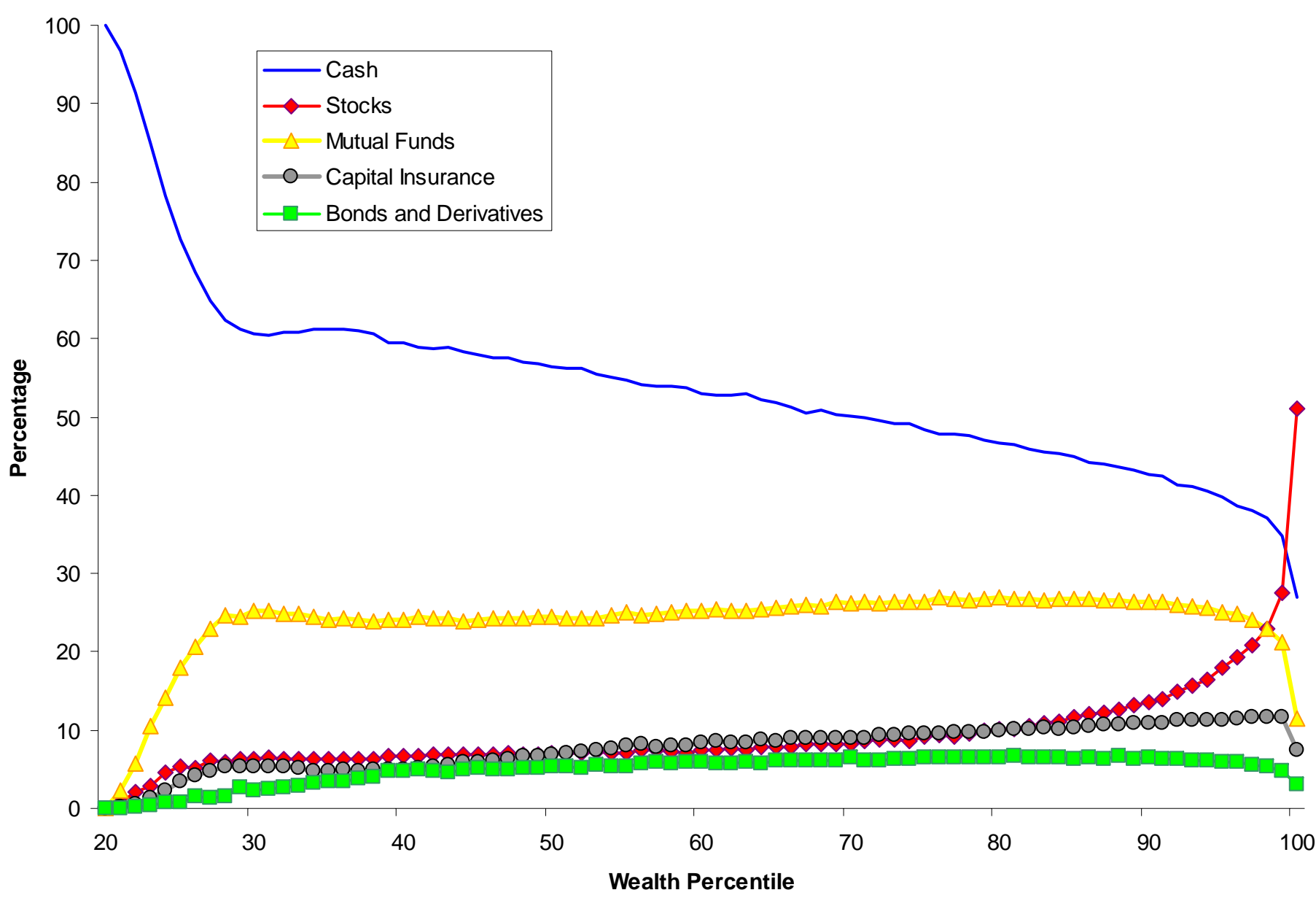




\section{B. Variation with Age of Household Head}

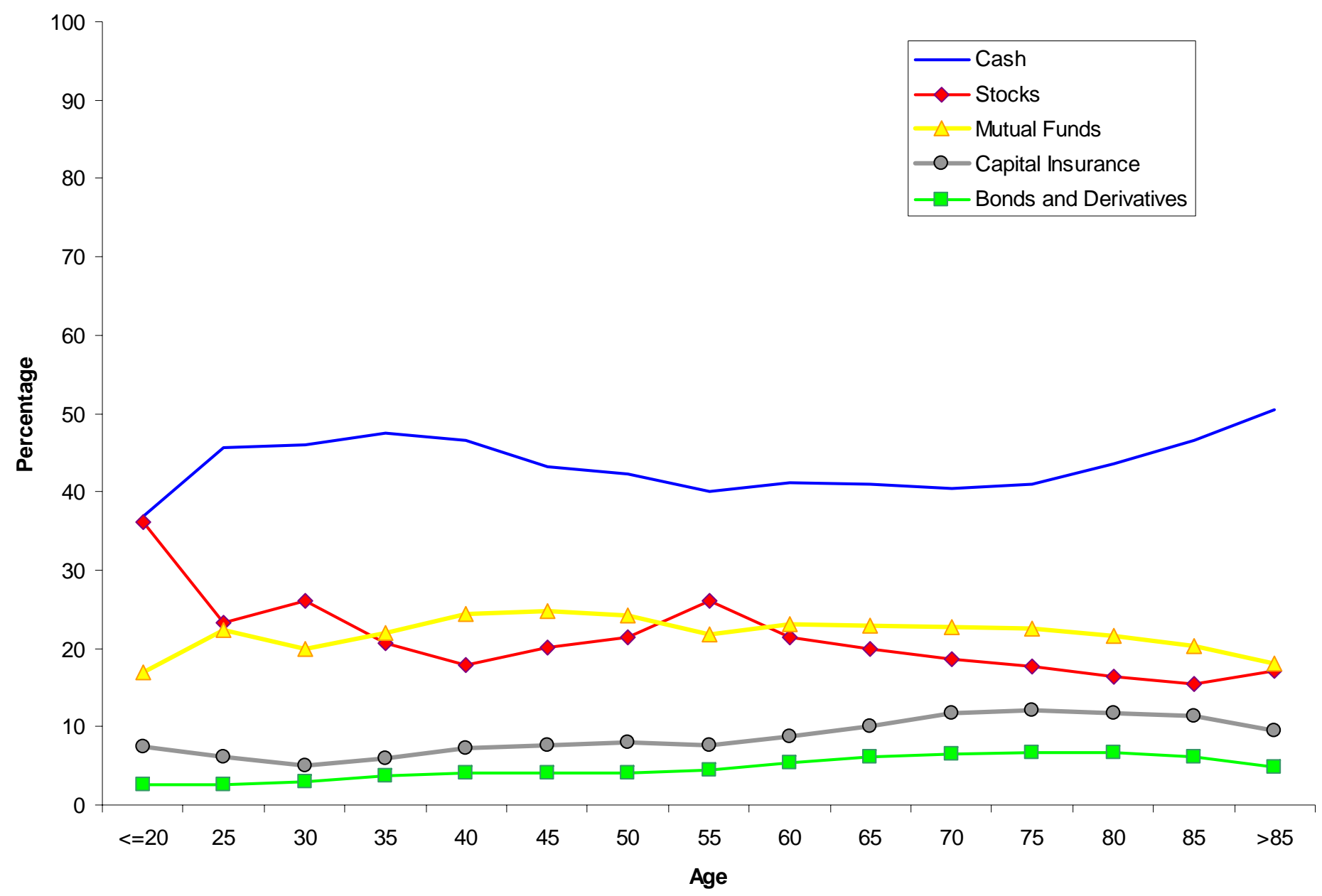




\section{FIGURE 4. VOLATILITY AND BETA OF RISKY PORTFOLIOS}

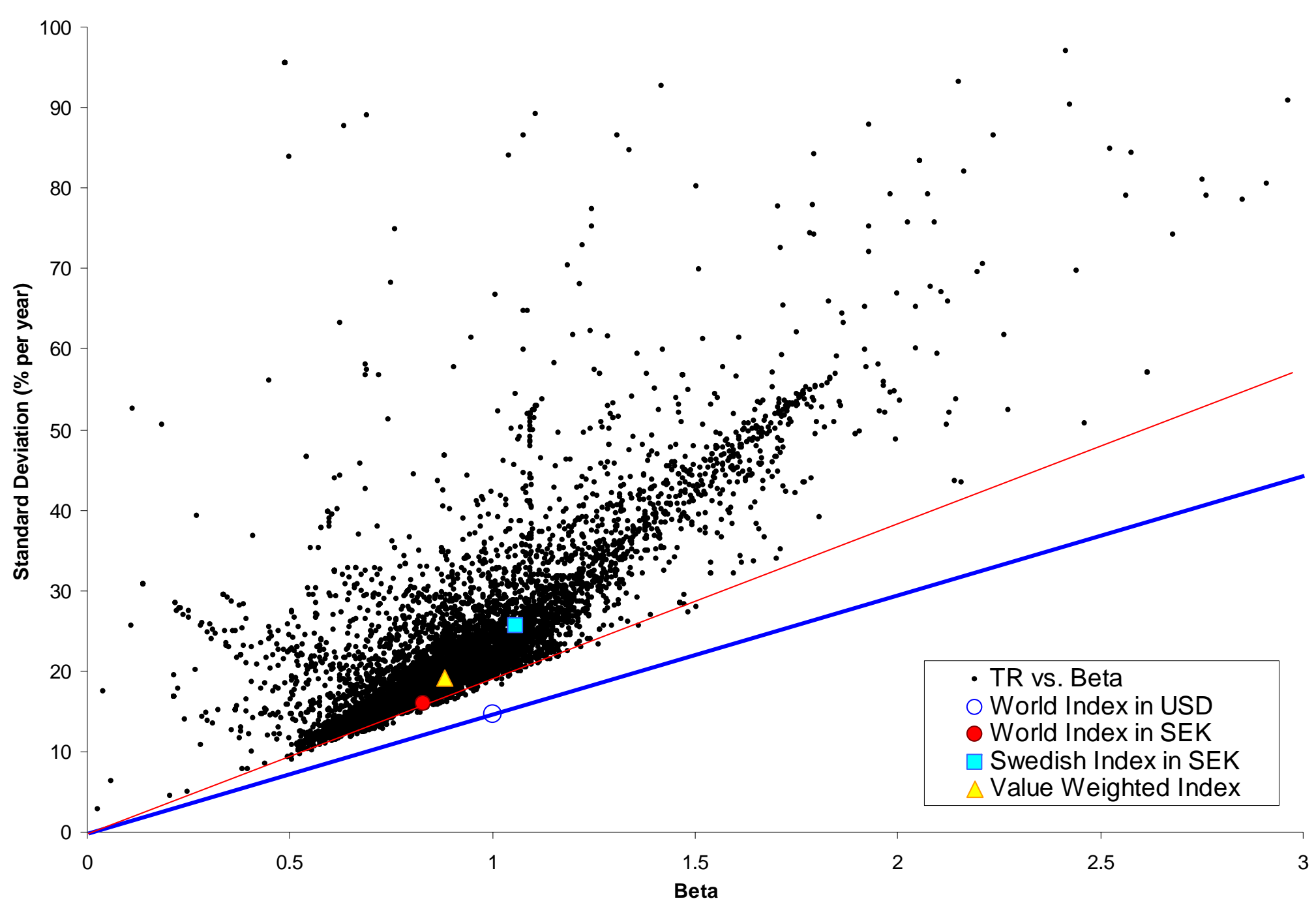




\section{FIGURE 5. SCATTER PLOTS OF HOUSEHOLD PORTFOLIOS}

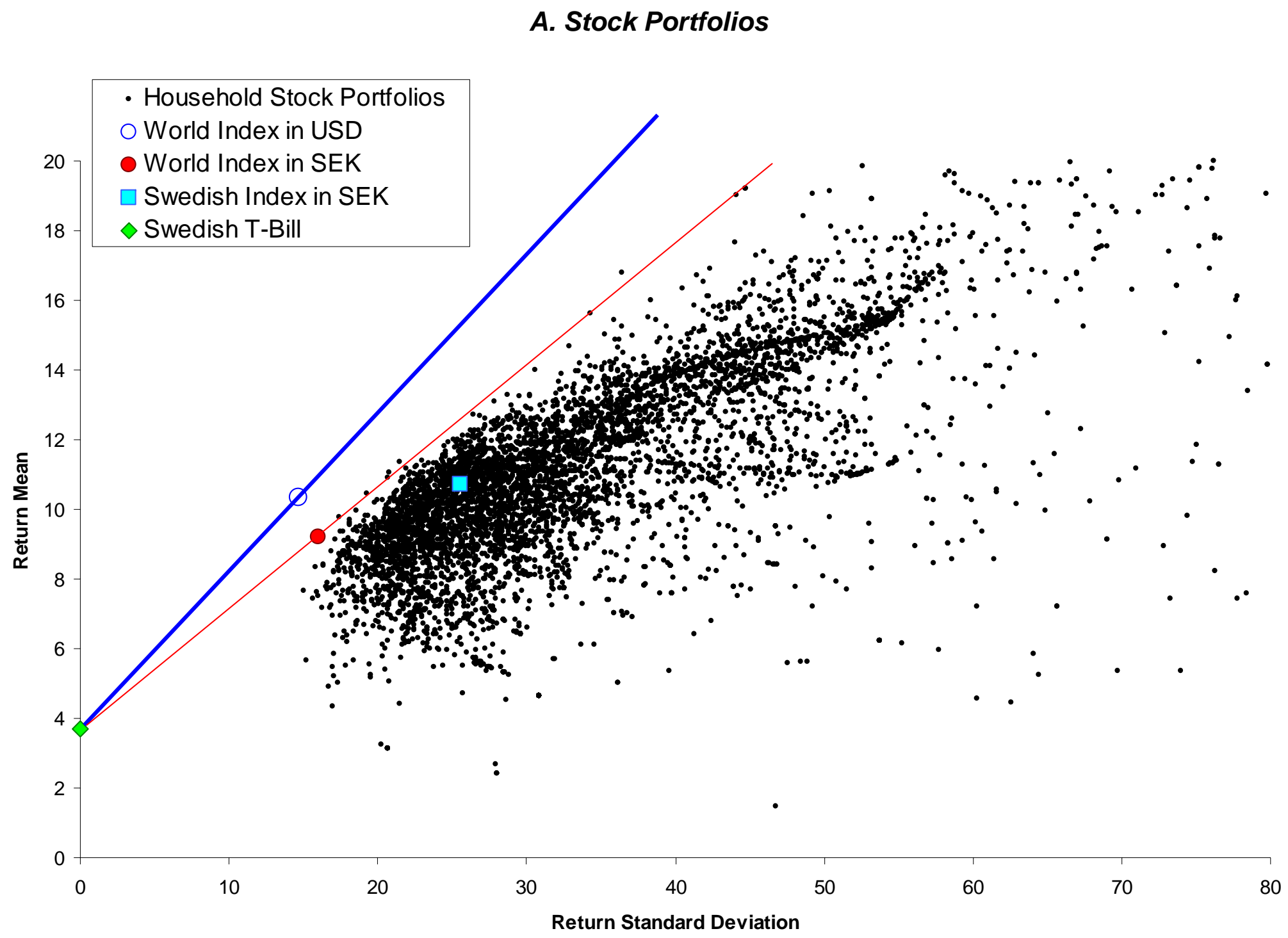




\section{B. Complete Portfolios}

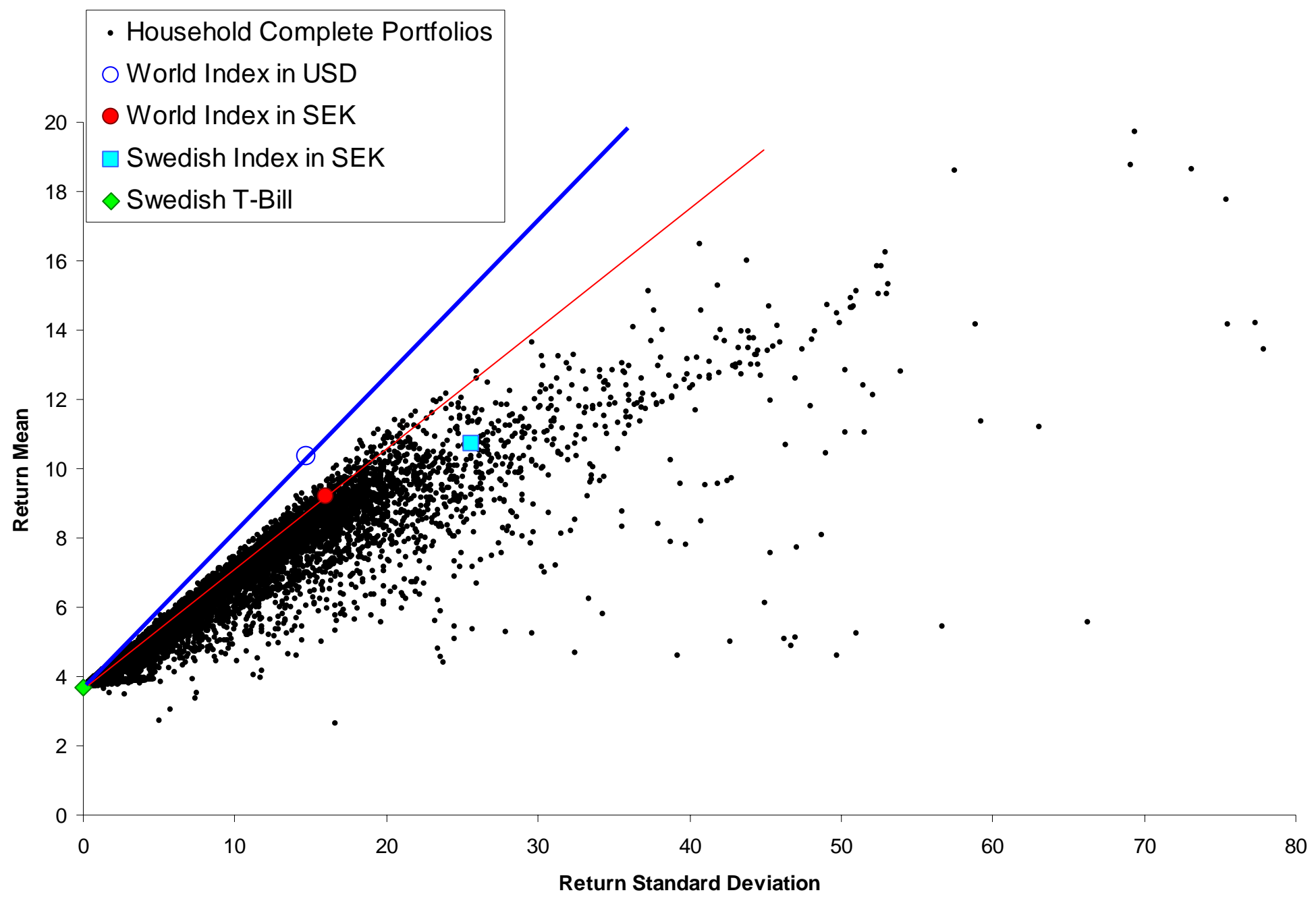

